\title{
Modernidad y Sufrimiento: Algunos elementos para la comprensión de la significación cultural de la experiencia del sufrimiento.
}

Tesis presentada para obtener el grado de Magíster en Antropología y Desarrollo, Santiago, Abril de 2002.

Daniela Thumala. Magíster en Antropología y Desarrollo, Universidad de Chile. Psicóloga, Universidad de Chile.

dthumala@soles.cl

Profesor Guía:Juan Carlos Skewes

\section{Agradecimientos}

Quisiera agradecer en primer lugar a Juan Carlos Skewes, profesor guía de esta Tesis, quien me brindó apoyo constante durante el proceso de elaboración del trabajo. Cada una de sus observaciones resultó fundamental y fueron dadas con oportunidad y buena disposición, lo cual facilitó enormemente el desarrollo y finalización de la Tesis.

A Aldo Mascareño y Ana Vergara por todos los aportes recibidos durante el Taller de Tesis.

A Marcelo Arnold y Francisco Osorio por la disposición para ayudarme en momentos de dificultad.

Por último, muy especialmente a Cecilia Dockendorff, mi madre, por su aporte y ayuda incondicional.

Palabras claves: Constructivismo/ Sufrimiento/Modernidad/ Cultura

\section{Resumen}

El trabajo que se presenta, se enmarca en una epistemología constructivista y propone una visión del sufrimiento humano como una experiencia construida y condicionada por la cultura. A partir de ello, se intenta fundamentar que es posible observar particularidades que son propias del sufrimiento moderno.

Si bien el ser humano siempre ha sufrido, muchas de las fuentes de sufrimiento actuales tienen que ver con características propias de la modernidad, tales como el riesgo y la incertidumbre que caracterizan ésta época, por mencionar algunas. En este contexto, no es difícil la aparición de síntomas como angustia, stress o depresión, los que se busca muchas veces anestesiar de alguna forma con el propósito de evadir y negar el sufrimiento. Este modo de enfrentamiento evasivo, se relaciona con un conjunto de ideas, creencias y supuestos culturales modernos que han cambiado la relación del hombre con el mundo y por ello también con el sufrimiento. En la modernidad el sufrimiento ha ido perdiendo sentido y el individuo se ha vuelto cada vez menos tolerante a él, por ello le resulta tremendamente difícil enfrentarlo cuando es inevitable. Sin embargo, existen ejemplos en que el sufrimiento es enfrentado de una forma que no sólo permite sobrellevarlo mejor, sino también desarrollar una visión más amplia de la vida. Estas experiencias probablemente están construidas a partir de supuestos que se contraponen a los modernos. Comenzar a evidenciar los supuestos de nuestra cultura puede aumentar la comprensión de nosotros mismos, así como la libertad para experimentar nuestra vida de otras formas posibles, en este caso nuestra experiencia de sufrimiento. 


\section{1- Introducción}

Un elemento central en los motivos de consulta de salud mental y en la falta de "felicidad", "contento" o "tranquilidad" que reportan muchas personas tener en sus vidas, es la presencia de sufrimiento psicológico. Es ácil observar como durante toda nuestra historia la humanidad ha venido experimentándolo y preguntándose por su sentido, con el propósito de mitigarlo o al menos entenderlo. Claramente son muchas las preguntas que surgen al intentar abordar un tema tan complejo como el sufrimiento humano.

Sin duda las preguntas relativas al sufrimiento surgen desde diferentes ámbitos. La filosofía, por ejemplo, puede reflexionar en torno a la relación entre el sufrimiento y el ser; la religión intentará darle un sentido trascendente; la biología y la medicina buscarán las diferencias de las personas en su respuesta al dolor físico; la psicología y la psiquiatría se centrarán en las respuestas individuales frente al sufrimiento. Cada una de estas disciplinas parece aportar un elemento que ayuda a formar una suerte de puzzle, no necesariamente coherente, de preguntas y respuestas sobre el sufrimiento psicológico.

Una pregunta que aparece como relevante es qué produce sufrimiento y cómo se responde y se enfrenta esta experiencia en una determinada cultura. Considerar esta pregunta desde una epistemología constructivista, nos remite a las diferentes posibilidades de construcción de la experiencia en que, tanto los factores individuales - biológicos y psicológicos - así como los culturales, juegan un papel determinante en la construcción de la experiencia del sufrimiento. Desde una perspectiva cultural, resulta interesante explorar aquellos elementos que forman parte de nuestra cultura moderna occidental y que influyen en la forma de significar el sufrimiento y por lo tanto de construir esta experiencia y responder a ella.

Es importante hacer referencia a la noción de sufrimiento psicológico que se está considerando para este estudio. Definir qué es sufrimiento siempre será una tarea de gran envergadura y afirmaciones discutibles. No obstante, para el propósito de este trabajo, es interesante la aproximación que realiza Le Breton (1999), la cual considera la perspectiva cultural en el proceso de significación de la experiencia, en este caso del sufrimiento. Desde su mirada, el sufrimiento puede ser entendido como la vivencia subjetiva de un evento que es percibido como doloroso, vivencia que se configura en un contexto social y cultural. Para este autor, no habría dolor sin sufrimiento, es decir sin un significado afectivo. Así, la significación que hace la persona, si bien es íntima, está impregnada de materia social, cultural, relacional y es producto de una determinada educación, por lo que no es ajena al vínculo social (Le Breton, 1999). El sufrimiento entonces, puede ser entendido como una experiencia que el individuo - como miembro de una cultura - construye al significar una percepción dolorosa.

Si se parte, entonces, del supuesto que el sufrimiento es una experiencia culturalmente condicionada, ¿Es posible afirmar que esta experiencia se ha visto afectada por la llegada de la modernidad?, ¿Existe una modernización del sufrimiento?. Si es así, ¿Cómo es el sufrimiento en la modernidad? ¿¿De qué manera la modernidad influye en la construcción de la experiencia del sufrimiento?, ¿Qué elementos de la modernidad podrían determinar la construcción de esta experiencia? ¿Se sufre más o de manera diferente o por causas distintas hoy respecto de un pasado premoderno o tradicional?, ¿Es posible caracterizar un sufrimiento moderno?, ¿Cómo responden o enfrentan las personas el sufrimiento en el contexto de la modernidad? 
El sufrimiento, desde las Ciencias Sociales, puede ser conceptualizado como una construcción cultural y social fundamentalmente desde la mirada de la Antropología y la Sociología. Estas disciplinas han aportado, a partir de sus investigaciones, por ejemplo, relaciones entre la percepción de incertidumbre con características culturales y factores de riesgo social (PNUD 98 por ejemplo). No se ha estudiado si ha habido una modernización del sufrimiento, más bien describen factores que inciden en él, pero, a partir de estos estudios es posible esbozar algunas respuestas a esta pregunta. Por otra parte, el sufrimiento ha sido abordado por la Psicología Clínica y la Psiquiatría, básicamente en investigaciones relativas al ámbito de la psicopatología. Desde este marco es posible suponer cómo una persona, de acuerdo a sus recursos psicológicos, experimentará y enfrentará una situación que le resulte dolorosa. Desde la perspectiva clínica, lo que interesa es poder realizar diagnósticos, estimar pronósticos y diseñar tratamientos para el alivio del sufrimiento de las personas considerando sus recursos psicológicos. Si bien la perspectiva clínica no pone el acento en la cultura, sus estudios permiten conocer cómo en ésta se define lo que es sufrimiento patológico y la cantidad y tipos de patología mental que hay en nuestra sociedad, lo cual puede ofrecer algunas pistas para la exploración de la relación entre sufrimiento y modernidad.

El presente trabajo intenta ser una sistematización conceptual referida a la relación entre el sufrimiento - entendido como una experiencia culturalmente determinada - y la modernidad, con el propósito de demostrar, a partir de la revisión bibliográfica realizada, que el sufrimiento en la modernidad toma características propias.

Para ello, en primer lugar se realiza una revisión de las principales características de la modernidad que resultan relevantes para la comprensión del sufrimiento moderno. Luego, se propone una concepción del fenómeno del sufrimiento como una experiencia culturalmente condicionada y se realiza una caracterización general del sufrimiento en la modernidad. Ahora bien, explorar la posible relación entre modernidad y sufrimiento requiere de la explicitación del marco epistemológico a partir del cual se sitúa el estudio. Para el propósito de este trabajo, el análisis se realiza desde una epistemología constructivista, que es descrita básicamente a partir de la biología del conocimiento.

Por último, se propone un modelo de observación con el que se intenta mostrar de qué forma algunos supuestos propios de la cultura moderna occidental participan en la construcción del sufrimiento de los individuos, dándole así un carácter moderno.

Abordar el estudio del sufrimiento incorporando la perspectiva cultural en la construcción de la experiencia del individuo, permite ampliar la comprensión del fenómeno al intentar integrar el análisis individual con el cultural. Como mencioné, el estudio del sufrimiento se ha abordado fundamentalmente desde la terapéutica o desde los fenómenos sociales que lo favorecen, pero no desde la perspectiva de la participación de supuestos culturales en la construcción de la experiencia de un individuo, donde la mirada tiende a reducirse a sus características biológicas y psicológicas dejando de lado la participación de la cultura. Intentar, de un modo preliminar, dar una mirada más integradora, puede ser un aporte al trabajo interdisciplinario entre la Psicología y la Antropología.

Finalmente, al ser consecuentes con una epistemología constructivista que nos sitúa como constructores de nuestras experiencias, tenemos un poder sobre éstas, poder del que no somos conscientes. En nuestra cotidianeidad, las personas vivimos la vida creyendo que lo que nos ocurre es nuestra única posibilidad de experiencia, sin saber que estamos atrapados en nuestras propias construcciones culturales que no vemos y por lo tanto no cuestionamos. Explorar si ha habido una modernización del sufrimiento y cómo éste puede ser comprendido, 
puede sacar a la luz elementos que enriquezcan la discusión relativa a este tema y nos otorguen mayor consciencia del poder que tenemos sobre nosotros mismos.

\section{2- Modernidad}

\section{1- Consideraciones previas}

El presente trabajo es una reflexión sobre la relación que afirmo existe entre la modernidad, como una característica central de la cultura occidental, y el sufrimiento humano. La relación entre sufrimiento y modernidad se caracteriza, en términos muy generales, por una importante y tal vez creciente dificultad para integrarlo como parte de la vida, tal como pretendo demostrarlo en este ensayo. Para ello, se hace necesario comenzar con una exposición de aquellos aspectos más relevantes que definen y caracterizan a la modernidad, para luego estimar de qué manera ésta se vincula con la experiencia de sufrimiento. Si bien una descripción de la modernidad puede constituir una gran tarea en sí misma, dada su complejidad, en este trabajo la descripción se centrará en aquellos aspectos de la modernidad actual que resulten relevantes para el análisis propuesto.

Ante la pregunta ¿qué es la modernidad?, lo primero a lo que se puede aludir, como señala Giddens (1994), es a los modos de vida y organización social que aparecen en Europa aproximadamente en el siglo XVII en adelante y cuya influencia los han convertido en prácticamente mundiales. Si bien, como menciona el autor, esta caracterización ofrece una noción témporo - espacial de la modernidad, no describe sus características más importantes, menos aún lo que caracteriza a la actualidad.

Al intentar realizar una descripción sobre lo que caracteriza a la modernidad actual, aparecen distintos períodos demarcados y diferentes nociones (modernidad reflexiva, tardía, posmodernidad) en función de aquellos elementos que más quiere destacar un autor. Beck (1999) por ejemplo, distingue dos épocas de lo moderno: la modernidad industrial (siglo XIX fundamentalmente) y la modernidad reflexiva (actual). Describe a la modernidad reflexiva como aquella en que la sociedad se autoconfronta con las "consecuencias de la sociedad de riesgo que en el sistema de la sociedad industrial, y por medio de las normas de allí institucionalizadas, no pueden ser elaboradas y transformadas" (pp. 33, 34). La sociedad se vuelve reflexiva al tomarse a ella misma como tema y problema. El concepto de modernidad reflexiva resulta, de este modo, consistente con el énfasis que Beck pone en el análisis del riesgo que está presente en la vida social moderna.

Es interesante, por otra parte, la discusión de la que da cuenta Brünner (1999) respecto del término postmodernidad. Plantea que existe polémica en torno al uso de este concepto que intenta caracterizar lo nuevo de nuestra época. Según el autor, cada vez que en la historia se ha querido bautizar una nueva era para poder dar cuenta de ella, ha surgido un conflicto entre la comunidad de intérpretes. Lo que finalmente resulta es, como en la mayoría de estas disputas, una aparición de dos bandos: Los que creen estar describiendo una verdadera novedad y los que creen que no hay nada nuevo bajo el sol y, que en el mejor de los casos, "la realidad sólo parece diferente por haber cambiado de ropaje." (p. 10) Por su parte Giddens (1995), usa el término modernidad tardía para referirse a la radicalización y universalización de las características centrales de la modernidad.

No corresponde a los propósitos de este trabajo una elección del término más adecuado. Dada la complejidad del tema, no es posible en este ensayo tomar una postura respecto a si la actualidad presenta características nuevas y estamos en la postmodernidad o si éstas sólo son 
un "cambio de ropaje" de lo que siempre ha sido la modernidad y en realidad se debe hablar de modernidad reciente o tardía o, como señala Beck, de modernidad reflexiva.

Más allá de las definiciones y discrepancias, lo que interesa, para la finalidad de este trabajo, es hacer una descripción de las características particulares de la actualidad que puedan vincularse a la experiencia de sufrimiento. Interesa mostrar cómo el sufrimiento, al ser una experiencia condicionada por la cultura, toma ciertas características que le son propias en el contexto de la modernidad. Ahora bien, sí es importante explicitar qué se entenderá por actualidad y dónde ésta se circunscribirá.

La descripción se centrará especialmente en aquellas características más específicas del período reciente, es decir del siglo XX en Occidente. No obstante, algunas de ellas que se observan hoy, son constitutivas de la modernidad entendida como el extenso período histórico que surge en Occidente luego de la Edad Media. Pero no es un período histórico el que interesa describir, sino más bien las características que rigen los modos de vida en el mundo occidental y que pueden observarse ya desde los comienzos de la modernidad, pero que serán en este trabajo mayormente ejemplificadas en el siglo XX.

Para ello se destacarán las ideas más relevantes de diferentes autores, por lo tanto, se denominará al período aludido con el término que cada uno le asigna para su descripción.

\section{2- Características centrales de la modernidad}

Para Giddens (1995), es posible usar el término "modernidad" como un equivalente aproximado a la idea de "mundo industrializado", mientras se entienda que la industrialización no se reduce a su aspecto sólo institucional. Ésta es entendida como la forma en que se configuran las relaciones sociales en el contexto del uso de la fuerza física y la maquinaria en los procesos de producción. En relación a ello, aparecen como ejes importantes el capitalismo - entendido como un sistema "de producción de mercancías que comprende tanto a los mercados de productos competitivos como a la transformación en mercancía de la fuerza del trabajo" (p. 27) - y el Estado nacional, como un nuevo orden de relaciones sociales. La "sociedad" en la modernidad es, para Giddens (1995), el Estado nacional, el cual "en tanto entidad sociopolítica, contrasta fundamentalmente con la mayoría de bs tipos del orden tradicional y nace sólo como parte de un sistema de un Estado nacional más amplio (que en la actualidad tiene un carácter mundial), posee formas muy específicas de territorialidad y capacidad de vigilancia y monopoliza eficazmente el control sobre los medios de coacción." (p. 27)

La historia de la humanidad está marcada por discontinuidades y las formas de vida que trajo la modernidad "arrasaron de una manera sin precedentes todas las modalidades tradicionales del orden social. Tanto en extensión como en intensidad, las transformaciones que ha acarreado la modernidad son más profundas que la mayoría de los tipos de cambio característicos de períodos anteriores. Extensivamente han servido para establecer formas de interconexión social que abarcan el globo terráqueo; intensivamente, han alterado algunas de las más íntimas y privadas características de nuestra cotidianeidad."(Giddens, 1994, p. 18).

Es importante aclarar desde un comienzo, que la visión de la modernidad que se presentará, aun cuando caracteriza un amplio período de tiempo y espacio, no supone considerarla como un solo bloque hegemónico. La complejización de los diferentes sistemas sociales impide pensar en la cultura, moderna occidental en este caso, como una sola unidad. En este sentido, si bien es posible establecer distinciones entre modernidad y premodernidad, éstas no son siempre tan claras. Al respecto y a modo de ejemplo, García Canclini (1990) usa el término 
"híbrida" para referirse a la mixtura que observa en Latinoamérica entre modernidad y premodernidad. La intención de abordarla en este trabajo como una sola unidad al hablar de "modernidad" y no de "modernidades" se relaciona con su propósito: establecer una relación entre el sufrimiento y la modernidad occidental, a partir de sus características centrales que la distinguen como tal y que la diferencian de otros períodos históricos, sin hacer referencia al modo que ésta presenta en diferentes espacios particulares.

De todas las características observables de la modernidad, Brünner (1999), destaca la globalización como una característica fundamental de este tiempo, la cual da cuenta de un capitalismo que se ha extendido por el planeta "envolviéndolo en la lógica de los mercados y las redes de información" (p. 11). La idea de postmodernidad (si se usa este término) alude al estilo cultural que corresponde a esta realidad global. Según el autor, una cultura "por necesidad descentrada, movible, sin arriba ni abajo, hecha de múltiples fragmentos y convergencias, sin izquierdas ni derechas, sin esencias, pluralista, autoreflexiva y muchas veces irónica respecto de sí misma." (p. 11)

Para Giddens (1994), si puede afirmarse que estamos entrando en una etapa de postmodernidad, ello significa que el desarrollo social "nos está alejando de las instituciones de la modernidad y conduciéndonos hacia un nuevo y distinto tipo de organización social." (p. 52). Describe esta etapa como aquella en que hemos descubierto que nada puede saberse con certeza debido a que "los 'fundamentos' de la epistemología han demostrado no ser indefectibles, que la 'historia' está desprovista de teleología, consecuentemente ninguna noción de 'progreso' puede ser defendida convincentemente; y que se presenta una nueva agenda social y política con una creciente importancia de las preocupaciones ecológicas y quizás, en general, de nuevos movimientos sociales." (p. 52)

Aparecen además, claros intentos por deshacer lo que queda del viejo mundo. De allí la aparición de grupos de vanguardia. La palabra deshacer es usada por Brünner como una forma de englobar términos actuales tales como: deconstrucción, desmitificación, discontinuidad, etc. Lo interesante es que tales términos aluden a un rechazo a elementos del mundo tradicional. Por otra parte existe una aceptación de las diferentes esferas culturales (de élite o de masas, seria o banal, pesada o liviana, etc.) Todas forman parte del espíritu de la época y son legítimas representaciones de ésta. (Brünner, 1999.)

La actualidad se caracteriza por un mundo que se separa cada vez más de lo conocido. Por ello se extienden cada vez más las palabras que parten con "pos": posindustrial, posracionalista, posmarxista, etc. Se sabe que hay algo nuevo que nace (no se conoce bien qué) porque todo lo antiguo, moderno hasta ayer, se termina: fin de la historia, fin de la Razón, muerte de Dios, de la metafísica, de las Luces, de la revolución, de las utopías. (Brünner 1999)

Es interesante, y no poco inquietante, observar cómo lo que aparecía como una promesa de la modernidad - el entierro de la religión y de la metafísica para dar paso a la ciencia como fuente de verdad - para Brünner (1999) dio resultados contrarios. A medida que se difunde el conocimiento hay mayor conciencia de que existen cosas que no podemos conocer. La razón tampoco ha podido por sí misma regalarnos certezas.

Del mismo modo, para Giddens (1995), la modernidad corresponde a un orden postradicional en el que la seguridad de las tradiciones o costumbres no ha podido ser remplazada por la certidumbre del conocimiento racional. En la modernidad el hombre vive en la duda radical, todo conocimiento es hipotético, puede ser cuestionado a la luz de nuevos descubrimientos, todo es 
tentativo, no hay verdades absolutas. Si se buscó en Occidente reemplazar los dogmas preestablecidos, en la modernidad lo que tenemos es la institucionalización de la duda.

No sólo nos enfrentamos a la pérdida de certidumbre, Beck (1999), señala al riesgo como un elemento central en la comprensión de la modernidad. Plantea que la producción de riqueza va acompañada de la producción social de riesgos. Se pregunta "¿Cómo se pueden evitar, minimizar, dramatizar, canalizar los riesgos y peligros que se han producido sistemáticamente en el proceso avanzado de modernización y limitarlos y repartirlos allí donde hayan visto la luz del mundo en la figura de 'efectos secundarios latentes' de tal modo que ni obstaculicen el proceso de modernización ni sobrepasen los límites de lo 'soportable' (ecológica, médica, psicológica, socialmente)?"(p. 26). Se trata de riesgos que son consecuencia del desarrollo técnico y económico de la modernidad.

Obviamente la presencia de riesgos no es propia de la modernidad, pero (más allá de desastres naturales), a diferencia de épocas anteriores los riesgos son de problemas globales de amenaza para toda la humanidad, muchos de ellos incalculables e impredecibles, como la fisión nuclear o el almacenamiento de basura atómica.

A diferencia de la pobreza, que diferencia unas clases de otras, los riesgos afectan tarde o temprano a quienes los producen o se benefician de ellos. "Los riesgos muestran en su difusión un efecto social bumerang: tampoco los ricos y los poderosos están seguros ante ellos (...) la miseria es jerárquica, el smog es democrático" (Beck, 1998, pp. 42, 43). Son riesgos que afectan a todos, más allá de su color o clase social.

La modernidad ha traído la inevitabilidad de vivir con peligros de alta intensidad que amenazan la vida de grandes poblaciones y que están alejados del control de las personas e instituciones. Giddens (1995), describe el mundo en la modernidad tardía como apocalíptico, no por encaminarse inevitablemente hacia la catástrofe, sino porque implica riesgos a los que las generaciones anteriores no tuvieron que enfrentarse.

Castells (1999), por ejemplo, refiere cómo la globalización ha socavado la autonomía y el poder en la toma de decisiones del Estado - nación, lo cual unido a la globalización de delitos, como el lavado de dinero, por ejemplo, da como resultado el tráfico de drogas, de armas, de materiales radioactivos, de órganos humanos, de seres humanos, de asesinos de alquiler y de todo aquello que resulte rentable. Por otra parte, también señala que la posibilidad de desastres ecológicos, asociados al fomento de la producción, es un riesgo moderno así como el de una destrucción masiva de la humanidad en una guerra nuclear.

El riesgo en la modernidad está básicamente ligado a incertidumbres generadas por el propio hombre. "La percepción de riesgo es provocada (...) por la propia capacidad de intervención humana en la sociedad y en la naturaleza (...) Así, mientras los temores de ayer, hace mil años, nacían de las calamidades y la impotencia del conocimiento, los miedos de hoy, en cambio, son los del capitalismo tardío, de la alta modernidad, de una civilización dominada por el conocimiento y la comunicación." (Brünner, 1999, pp. 38, 39). Tal como señala Beck (1998), los bosques, por ejemplo, están muriendo desde hace muchos siglos, pero la muerte actual sucede de manera global, como una consecuencia implícita de la industrialización.

Si antes se podían atribuir los riesgos a la falta de abastecimiento, hoy tienen su origen en la sobreproducción industrial, "los riesgos de hoy difieren de los de la Edad Media (que a menudo se les parecen exteriormente) por la globalidad de su amenaza (seres humanos, animales, plantas) y por sus causas modernas. Son riesgos de la modernización. Son un producto global 
de la maquinaria del progreso industrial y son agudizados sistemáticamente con su desarrollo ulterior." (Beck, 1998, p. 28). No es, como se muestra, que en la modernidad existan más riesgos que en épocas anteriores. Lo distinto es que pensar en términos de evaluación de riesgos resulta una práctica generalizada en nuestros tiempos.

Giddens (1995), también por su parte señala que aún cuando la propia modernidad ha reducido un conjunto de riesgos, al mismo tiempo ha producido y se enfrenta a otros que no se conocían antes. Lo importante es que el concepto de riesgo resulta fundamental para la forma en que se organiza el mundo social. En la modernidad, el futuro es traído permanentemente al presente, como si se colonizara un territorio en el que la evaluación de los riesgos y probabilidades de concreción de los propios proyectos es central. Esta evaluación de riesgos se presenta en un contexto en el que las instituciones presentan características muy diferentes a todas las formas de orden social anteriores, básicamente "por su dinamismo, el grado en que desestiman los usos y costumbres tradicionales y su impacto general." (p. 9). En este sentido, para Giddens una de las características más evidentes de la modernidad es su carácter "desbocado": tanto la velocidad de los cambios sociales como sus metas y profundidad con que se ven afectadas las prácticas sociales difieren a las prácticas y comportamientos antes existentes. Este dinamismo implica que la mayoría de las formas de evaluación de riesgos esté sujeta a una gran cantidad de imponderables. Así, estamos insertos en un devenir que tiene consecuencias inesperadas y, tal como refiere Brünner (1999), la modernidad ha sido una cadena ininterrumpida de cambios en una dirección que no controlamos.

Por último, un aspecto que vale la pena destacar es que en las definiciones de lo que constituye riesgo "se rompe el monopolio de la racionalidad de las ciencias" (Beck, 1998, pp. 35). Por más que intenten los científicos una objetividad en lo que respecta a los riesgos, siempre quedan expuestos a expectativas y valoraciones sociales y que por lo tanto les están dadas, como por ejemplo, ¿cuáles son los límites entre los daños aceptables y los no aceptables?. La pretensión de racionalidad de las ciencias de conocer objetivamente el contenido del riesgo se ve permanentemente debilitada. No hay una respuesta certera.

En este contexto paradójico de la modernidad en el que, como se mencionó, el hombre ha reducido un gran número de riesgos pero a la vez ha generado otros nuevos, en el que la razón y la ciencia iban a ofrecer certezas y en cambio han llegado de la mano con la incertidumbre, el hombre es concebido como un ser libre y por lo tanto responsable, en gran medida, de su suerte. Aún cuando la idea de destino - que corresponde a un orden tradicional - no ha desaparecido del todo, la modernidad sitúa al individuo como responsable de evaluar las posibilidades y riesgos de las elecciones que toma para su vida futura. Hay pocas situaciones en que una decisión sobre lo que se ha de hacer queda en manos de alguien definido como un experto. Por lo general, la información de la persona o sistema experto ayuda en la evaluación de los riesgos, pero quien lleva la responsabilidad de la decisión es el individuo afectado por éstos (Giddens, 1995). El fracaso personal, la responsabilidad por la propia tragedia, es propio de la modernidad, no caracteriza a la cultura premoderna o tradicional en la que la libertad personal se ve reducida por la idea de destino o por un mayor sentido de trascendencia.

Junto a la incertidumbre, riesgos y falta de certezas se observa en la actualidad según Brünner (1999) el fin de los grandes relatos. Nuestra actualidad se caracteriza por la idea de que ya no se puede echar mano a aquellos conceptos que articularon el proyecto de la modernidad, tales como: progreso, racionalización, desarrollo, ciencia. Se observa en cambio, lo minoritario, lo fragmentado, lo diferente, es decir, lo que resta de la deconstrucción. 
El clima de la modernidad es, para Brünner (1999), la falta de un sentido. El fin de los grandes relatos, la falta de cabida para a pretensión totalizante de la razón, va de la mano con un espíritu que concibe el mundo como una infinita red de interpretaciones y micronarraciones. Nada es verdadero en sí, solamente contamos con descripciones y re - descripciones. Se liga a ello, una falta de sentido de futuro. Los hechos no van más allá de lo anticipado. Se observa un rechazo a significar los acontecimientos o, a la inversa, una tendencia a significar cualquier cosa. Hay una falta de perspectiva, hay intrascendencia y valoración de lo vulgar más que de la distinción, se desconfía de la verdad y se ironiza en vez de creer, "(...) una modernidad que acepta la pérdida de sentido, de valores y de realidad con una jovial osadía..." (p. 54)

Ligado a la pérdida de verdades y certezas, en la modernidad hay una pérdida de la presencia de una autoridad a quién referir la incertidumbre de la vida. En el mundo tradicional, una institución específica de autoridad que destacaba era la religión. En prácticamente todas las culturas premodernas existía un sólo orden religioso el que, aún contando con detractores, éstos no constituían una amenaza para el sistema de creencias dominante. Si bien la autoridad religiosa no eliminaba la incertidumbre de la vida en lo cotidiano, daba una respuesta a lo que estaba fuera del control humano. En la modernidad, también existen sistemas de autoridad entre los que se encuentra la religión pero, la diferencia fundamental con el mundo tradicional está en que en la actualidad las formas tradicionales de autoridad son hoy una forma de autoridad más entre otras. Los sistemas expertos constituyen autoridades en la modernidad pero, están lejos de la posibilidad de ofrecer certezas absolutas. Por supuesto no se vive en la cotidianeidad bajo una permanente sensación de incertidumbre o duda constante, éstas se resuelven mediante una mezcla de rutina y entrega a un cierto tipo de estilo de vida, que contempla la evaluación de ciertos riesgos y determinados sistemas expertos. (Giddens, 1995), pero que es resuelto por el individuo y no por una única autoridad.

Beck (1999), afirma que la sociedad moderna, así como vive de los recursos naturales que ha consumido y destruido, también consume sus propios recursos morales, los que tampoco es capaz de reponer. Para Brünner (1999), las esferas de valor, al pasar a formar parte del ámbito de lo interpretable en cuanto a sus significados, se transforman en algo lábil dando lugar a "culturas pluralistas, des - tradicionalizadas, hiper - críticas y sub - realistas." (p. 22). El fin de los grandes relatos parece poner fin, también, a los discursos morales. Para el autor, el hecho de descubrir que nuestros sistemas de valores son producciones humanas, puede ligarse a una suerte de incertidumbre moral la que constituiría una de las raíces profundas y poco visibles de las sensaciones de miedo y angustia de la posmodernidad.

Un elemento que destaca Brünner (1999), que resulta útil para una reflexión respecto de la moral en la modernidad tardía es el individualismo. Como tal, saca a la persona de un mundo de significados que comparte con otros situándolo en uno en el que predominan las elecciones personales. El sujeto se vuelca sobre sí mismo. Se potencia una cultura narcisista y de intercambios en la que poca cabida tienen las motivaciones trascendentes. El aumento infinito de opciones, producto de la expansión del mercado, orienta a la persona a la adquisición de satisfacciones de toda clase de fantasías por medio del mercado. De esta forma, se instala, valida y refuerza un estilo de vida hedonista.

Un claro ejemplo de la generalización de la búsqueda de satisfacciones a través del consumo puede observarse en el comportamiento sexual. Castells (1999), revela datos en el ámbito de la sexualidad que apuntan al alza de un consumismo, experimentación y abandono del espacio de la pareja estable en búsqueda de nuevos modos de expresión en el ámbito sexual, a lo que llama "sexualidad consumista". 
Para Brünner (1999), el aumento de la mercantilización del mundo se ha visto asociado a una disolución de las Igaduras que vinculan a las personas con su propia cultura. Estas ligaduras son las que unen al individuo a un grupo o cultura más allá de sus propias opciones. No se participa en ellas por una elección propia, por ejemplo a la familia, a una determinada dase social, a una religión, a un género. Del mismo modo, estas ligaduras tienen que ver con tradiciones, pautas de comportamiento, convenciones y ritos de un determinado grupo. Socializan en una determinada orientación cultural y ayudan a definir el carácter de una persona. Otorgan seguridad y certidumbre a la estructura normativa de una sociedad.

Por el contrario, la noción de un universo pluralista, con múltiples posibilidades de elección, crea un marco referencial nuevo, diferente. Las relaciones deben ser inventadas, convenidas y mantenidas sin el apoyo de estructuras externas que las soporten. No es la tradición la que regula sino un compromiso personal. "En general, aparece una actitud constructivista respecto a los vínculos, como testimonia ampliamente el movimiento hacia la 'terapeutización' de las relaciones humanas. Las ligaduras salen del campo orgánico de la sociedad. Pierden su referencia jerárquica a la tradición, la naturaleza o Dios. Ellas mismas devienen objeto de intervención experta. Es el momento de auge de las 'relaciones humanas', de la introspección y del ego - centrismo" (Brünner, 1999, p. 76). Como resultado, las relaciones se tornan más frágiles, intercambiables y de mayor flexibilidad adaptativa en una sociedad de cambios y variadas opciones.

Respecto de los cambios observables en el ámbito de las relaciones humanas, Castells (1999), realiza una extensa y clara descripción de lo que él llama "El fin del patriarcado". Entiende al patriarcado como una estructura básica de las sociedades contemporáneas, caracterizada por la autoridad de los hombres sobre las mujeres y sus hijos al interior de la familia. Esta autoridad es aceptada en tanto domina toda la organización de la sociedad.

El fin de esta forma de organización, principalmente en países desarrollados, es, para Castells (1999), un fenómeno irreversible y constituye una revolución importante, ya que llega a la raíz de la sociedad y al núcleo de lo que somos. Afirma que el fin del patriarcado se debe principalmente a la combinación de cuatro elementos: la apertura de oportunidades de educación para las mujeres, el control de la reproducción, el desarrollo del movimiento feminista y la rápida difusión de ideas en la cultura globalizada. (1) Cada uno de estos elementos ha influido en que actualmente la familia patriarcal esté en crisis. No resulta una novedad constatar que existe un aumento del número de divorcios en los países occidentales (Beck, 1998). Para Castells (1999) "La disolución de los hogares de las parejas casadas, por divorcio o separación, es un primer indicador de desafección a un modelo de familia que se basaba en el compromiso, a largo plazo de sus miembros." (p. 163). Sin duda, como señala el autor, lo que ocurre muchas veces es un patriarcado sucesivo, con la reproducción del mismo modelo con nuevos miembros. Sin embargo, la estructura de dominación se ha visto debilitada por la experiencia de mujeres y niños que se ven atrapados en un conflicto de lealtades. Muchas veces lo que se observa es, luego de la separación, la formación de hogares unipersonales o uniparentales, por lo general de mujeres.

La frecuencia de las crisis matrimoniales y la dificultad para compatibilizar el matrimonio con el trabajo se asocia otras tendencias: el retraso en la edad para la formación de pareja y matrimonio, la convivencia sin matrimonio - lo que debilita la autoridad patriarcal al no establecerse la relación bajo un marco legal (2) -, la variedad creciente de estructuras de hogares, equivalentes a lo que Beck (1999), señala como una "creciente pluralidad de situaciones". Situaciones en la que es probable que surjan y existan al mismo tiempo un gran 
número de formas familiares de convivencia donde, por ejemplo, las paternidades con uno o dos divorcios de por medio sean integradas como diversas fases en una vida (Beck, 1999). Castells (1999) por su parte hace referencia a familias con hijos nacidos fuera del núcleo de la familia patriarcal - dada la mayor autonomía de las mujeres - el aumento de niños criados con sólo uno de sus padres, la mayor tolerancia al establecimiento de parejas homosexuales muchas de las cuales no renuncian a la crianza de hijos - la disminución de las tasas de fecundidad en países desarrollados, por mencionar los elementos más destacables, todos claramente contrapuestos a la familia patriarcal.

Para Castells (1999), es así como en la mayoría de los países desarrollados la familia patriarcal está transformándose en una forma de vida minoritaria. ligado a la aparición de cada vez más alternativas que son aceptadas como formas de asociación entre las personas para compartir su vida y criar a los hijos. No se trataría de la desaparición de la familia, sino de su diversificación y cambio en la autoridad que tradicionalmente la regía. Del mismo modo, Beck (1999) señala que aunque se cuestione el matrimonio, la mayoría de los jóvenes quiere una vida compartida con otros, "(...) el ideal de la relación estable sigue estando hoy en primer plano" (p. 134).

Sin embargo, frente al fenómeno de crisis de la familia patriarcal, no ha surgido una sola alternativa, la regla es la diversidad de modos de vida. En este contexto, resulta interesante que los modos de organizarse dentro de la familia (distribución de roles y responsabilidades), al no ajustarse a la tradición, pasan a ser otro espacio de elección y negociación de los intereses de las partes, lo que aumenta la complejidad de las relaciones al interior del grupo familiar. En este sentido, Giddens (1995) señala que la mayor posibilidad de elecciones ofrece una oportunidad de expresión que faltaba en los medios más tradicionales, pero, al mismo tiempo, las relaciones resultan en cierto sentido más arriesgadas y peligrosas. "Los modos de comportamiento y sentimiento asociados a la vida sexual y marital se han convertido en algo movedizo, inestable, 'abierto'. Hay en ellos mucho que ganar, pero también nos encontramos aquí en un territorio aún por cartografiar y con nuevos peligros que correr" (p. 24).

La forma en que la modernidad ha afectado la vida personal, puede ya suponerse a partir de lo descrito, sobre todo de aquello referido a los cambios al interior de la familia, la que de alguna manera es y ha sido el espacio de desarrollo de la vida personal e íntima de los individuos. Es la intimidad de los individuos, su vida diaria, la que toma características particulares en la modernidad y por ello también sus experiencias de sufrimiento. Corresponde por lo tanto, ofrecer a continuación, una descripción de la persona en el mundo social moderno, ya que es ésta, inserta en la cultura moderna, el foco de interés de esta discusión.

\section{3- La Persona en la Modernidad}

Para Giddens (1995), es posible observar cómo en la modernidad aparece una interconexión entre dos extremos, por un lado las influencias globalizadoras y por otro las disposiciones personales. Los cambios provocados por las instituciones modernas se "entretejen", como señala el autor, con la vida personal y por lo tanto con la identidad individual o el "yo". La influencia de los acontecimientos distantes sobre la propia intimidad se ha convertido progresivamente en algo común, cotidiano. La mundialización y la transformación en la identidad del yo, que a continuación se describe, son, para Giddens (1995), dos polos relacionados, entre lo local y lo universal en la modernidad reciente.

En un contexto de riesgo e incertidumbre y en el que la tradición ha venido perdiendo poder como instancia normativa o reguladora de la propia identidad, el individuo se ve enfrentado a 
tener que estructurar cada vez más por sí mismo una forma de ser, una manera de concebirse y a darle, además, un sentido a su vida que no viene dado. Al respecto, para Giddens (1995), el desarrollo del yo se convierte en la modernidad en un tarea refleja. Ello consiste en la mantención de una biografía coherente, que constantemente es revisada y que ocurre en un contexto de múltiple elección. En épocas premodernas, los momentos de transición o cambio de las vidas individuales (los que siempre requieren de una reorganización psicológica) eran resueltos a través de "ritos de paso". En estas sociedades, en las que las cosas se mantenían más o menos de la misma forma generación tras generación en el ámbito de lo colectivo, los cambios en la identidad individual estaban claramente definidos y marcados (por ejemplo el paso de la adolescencia a la vida adulta). En la modernidad sin embargo, los cambios en la identidad del yo deben ser explorados y construidos como parte de un proceso reflejo, con el propósito de vincular el cambio individual con el medio social.

De este modo, en la modernidad la noción de un "estilo de vida" adquiere especial importancia: Giddens (1995) entiende por "estilo de vida " un conjunto de prácticas más o menos integrado que una persona adopta no sólo motivado por necesidades de tipo pragmáticas, sino porque dan una coherencia a la identidad el yo. Sostiene que la planificación de la vida, al ser organizada de manera refleja, presupone una ponderación de riesgos que es sopesada por el contacto con el conocimiento de los expertos, lo que constituye un comportamiento característico del proceso de estructuración de propia identidad. La pregunta referida al cómo se ha de vivir no sólo puede implicar un cuestionamiento sobre el sentido de la propia vida, sino decisiones diarias respecto a cómo comportarse, qué comer, qué vestir, etc., durante el tiempo. La elección pasa a ser parte de la actividad cotidiana de los individuos. Es claro que no existe ni ha existido una cultura en que haya eliminado todas las elecciones de la vida diaria, sin embargo la tradición o los hábitos establecidos ordenaban la vida dentro de ciertos márgenes relativamente impuestos. En la modernidad, el individuo está frente a una compleja diversidad de opciones y al carecer ésta de un carácter impositivo, ofrece poca ayuda respecto a qué opciones conviene tomar.

Al respecto Beck (1999), describe cómo en la actualidad lo que antes era resuelto en el contexto de la familia, de la comunidad aldeana o dentro de la propia clase o grupo social, hoy debe ser resuelto por el propio individuo al que se le exige "que sea él quien domine la inseguridad" (Beck, 1998, p. 200) (3). Afirma además: "Estas 'riesgosas libertades' son imputadas ahora a los individuos sin que éstos, sobre la base de la extrema complejidad de la sociedad moderna, estén en condiciones de tomar las inevitables decisiones de manera responsable, esto es, considerando las posibles consecuencias" (p. 36).

El hecho de "tener que elegir" un estilo de vida toma un lugar central en este contexto. Elección en la que es imposible no participar. En condiciones de la modernidad de alguna manera todos nos vemos forzados a optar por diferentes prácticas, no hay más elección que elegir. Todas estas elecciones son relativas no sólo a cómo actuar, sino también a quién ser. Mientras más postradicionales sean las características de la sociedad en la que se encuentra el individuo, más importancia tendrá el estilo de vida en el núcleo mismo de la identidad del yo. Por supuesto que las elecciones posibles no son las mismas para todos las personas, las variaciones de estilos de vida que se observan entre diferentes grupos son el resultado muchas de las veces de la estratificación social.

En la modernidad surgen tendencias individualizadoras que impulsan a los individuos, en aras de la propia supervivencia, a hacer de sí mismos el centro de sus propios planes y estilo de vida. Además, como sostiene Beck (1998), la agudización y la individualización de las desigualdades sociales se entremezclan y una de sus consecuencias es que los problemas del 
sistema social son significados como fracaso personal. En este contexto, sostiene que se vuelven necesarias para la vida la adquisición de nuevas capacidades, tales como la capacidad de anticipar peligros así como de soportarlos. Para Beck (1998), la capacidad para tratar con la incertidumbre y con el miedo se convierte en lo que llama una "cualificación civilizatoria clave", por lo que la formación de ella se convierte en una importante tarea para las instituciones formadoras.

Junto a esta tendencia individualizadora, en la modernidad ocurre lo que Giddens (1995) llama una transformación de la intimidad. Este fenómeno, al igual que la identidad del yo, también se constituye como una tarea refleja en el sentido que adopta sus propias formas de organización interna. Aparece la "relación pura" como algo que caracteriza las relaciones personales. En la relación pura, han desaparecido los criterios externos, ella existe por la sola recompensa de tenerla. Brünner (1999), también alude a el concepto de relación pura para describir a aquellas relaciones postradicionales o postnormativas. Para Giddens (1995), en estas relaciones la confianza es lo que las sostiene, noción que por definición no se ancla en criterios externos tales como el parentesco, por ejemplo, y sólo puede activarse en un proceso de apertura por las diferentes partes involucradas. Si antes la tradición y las costumbres otorgaban seguridad al individuo, hoy, la noción de confianza en las relaciones y en los sistemas abstractos pasa a ocupar su lugar. La creciente preocupación por el tema de "las relaciones", como se mencionó anteriormente, expresa este fenómeno.

A partir de lo descrito, se puede comprender que la noción de confianza ocupe un lugar significativo en el desarrollo de la personalidad del individuo, más aun en las circunstancias de incertidumbre y riesgo de la modernidad. Por ello, las primeras etapas de vida del individuo son fundamentales en la adquisición de la sensación de confianza, la que resultará fundamental para enfrentar las amenazas que se le presentarán durante su vida, " (...) la confianza es el fundamento de una 'coraza protectora' siempre dispuesta a defender al yo en sus relaciones con la realidad de cada día". (Giddens, 1995, p. 11).

La confianza no sólo será un elemento constitutivo de las relaciones, será también aquello que nos ayuda a sobreponernos a los sentimientos de angustia y miedo propios de este tiempo. La experiencia, por una parte, de grandes ámbitos de seguridad se contrapone a la conciencia en el individuo, en menor o mayor grado, de duda, incertidumbre y riesgo. De acuerdo con Giddens (1995), la duda radical se introduce en la vida cotidiana, al menos como un telón de fondo. Incluso, agrega, para los creyentes más fundamentalistas es probablemente imposible eludir del todo la duda radical.

Globalización y modernidad actual o postmodernidad, como señala Brünner (1999), son dos fenómenos de los que difícilmente alguien puede quedar al margen. Como el mismo autor afirma "(...) la globalización relativiza todo lo que toca en su movimiento expansivo, desde la metafísica hasta la música; la postmodernidad, por su parte, tiene su origen en la auto conciencia de ese relativismo cultural." (p. 12). Así globalización y desarrollo de la propia identidad se "entretejen", como señala Giddens. En este tiempo de riesgos e incertidumbre, el individuo requiere, en mayor o menor grado, armarse a sí mismo sólo, compartiendo espacios de intimidad que no vienen dados ni garantizados, que también debe construir. Debe elegir, es paradójicamente forzado a ser libre y cualquier fracaso es entendido como un fracaso personal, individual.

Lo que intentaré demostrar a partir de esta caracterización de la modernidad, es que es posible desprender de ella aspectos que se ciernen amenazantes sobre los individuos y cuya respuesta los aproxima a nuevas formas de enfrentar el sufrimiento. El hombre moderno, al igual que 
aquellos que le precedieron, ha tenido que enfrentar en lo más íntimo de su existencia el sufrimiento personal y, en el contexto de la modernidad, tanto las fuentes de sufrimiento, la forma de experimentarlo y por ello de enfrentarlo, tienen características que le son propias.

\section{El Sufrimiento como una construcción cultural}

\subsection{Conceptualización del sufrimiento en este trabajo}

Para realizar un análisis sobre la relación entre modernidad y sufrimiento, primero se debe aclarar qué es lo que se entenderá en este trabajo por sufrimiento. Tarea nada de fácil si se parte de la idea que cualquier experiencia humana reviste una gran complejidad, por lo que intentar enmarcarla en una definición siempre será, querámoslo o no, un acto reduccionista.

Las experiencias humanas están configuradas a partir de múltiples factores y además, cada una de estas experiencias tiene un carácter único y muchas veces poco definible. Tal como enuncié en la Introducción de este trabajo, diferentes disciplinas se aproximarán a los fenómenos a partir de sus propias distinciones y se centrarán por eso mismo en aquellos aspectos que les resulten más relevantes para sus propios análisis. La misma palabra "sufrimiento" tendrá diferentes significados para un filósofo que para un médico. Cada uno hará sus propias distinciones a partir de los ámbitos disciplinarios en que se encuentran. Por otra parte, si en distintos ámbitos la palabra "sufrimiento" puede tener diferencias de significado, más diferencias habrán entre cada una de las personas que definan esta compleja experiencia.

Parece imposible juzgar cuál aproximación es la "verdadera", cada una puede ser más o menos válida para un determinado contexto. En este sentido, estimo que el propósito no debe ser la búsqueda de la definición "real" de lo que significa la palabra "sufrimiento", en cambio sí creo posible ofrecer una conceptualización que resulte válida para el análisis que me propongo hacer. Por válida entiendo aquella definición que refleja en sí misma la idea que se tiene de un fenómeno y que resulta coherente y comparable con las definiciones más usadas con propósitos de análisis similares. Ahora bien, la validez de un concepto no nos liberará de caer en un reduccionismo. Siempre se estará aludiendo a lo que se entiende por un determinado fenómeno, por ello la validez de una definición es un criterio de elección que, creo, es más posible de ser evaluado que el de "verdad".

Asumiendo la imposibilidad de evitar el reduccionismo, estimo que para los propósitos de este trabajo, la conceptualización de sufrimiento que ofrece Le Breton (1999) ofrece ciertas ventajas que la hacen válida para dar cuenta de la relación entre modernidad y sufrimiento. En primer lugar, su mirada incorpora la perspectiva cultural. Le Breton (1999), entiende el sufrimiento como la significación que un individuo da a una experiencia que percibe como dolorosa. Afirma que siempre que un individuo tiene una percepción dolorosa le atribuye un significado, no hay dolor sin sufrimiento, es decir sin la atribución de un significado, en este caso, afectivo. Esta vivencia subjetiva se configura en un contexto social y cultural, por ello la significación que hace la persona, aún cuando es íntima, está impregnada de materia social, cultural, relacional y es producto de una determinada educación, por lo que no es ajena al vínculo social (4). El sufrimiento entonces, puede ser entendido como una experiencia que el individuo - como miembro de una cultura - construye al significar una percepción dolorosa.

En segundo lugar, su aproximación es lo suficientemente amplia, por lo que aún en la experiencia física del dolor - en la que la equivalencia biológica entre los seres humanos nos lleva a una vivencia física supuestamente parecida - la significación que le demos a ese dolor determinará en gran medida nuestra experiencia de sufrimiento. "No hay dolor sin sufrimiento, 
es decir sin significado afectivo que traduzca el desplazamiento de un fenómeno fisiológico al centro de la conciencia moral del individuo... El dolor que sentimos no es, entonces, un simple flujo sensorial, sino una percepción que en principio plantea la pregunta de la relación entre el mundo del individuo y la experiencia acumulada en relación con él. No escapa a la condición antropológica de las otras percepciones. Es simultáneamente sopesada y evaluada, integrada en términos de significación y de valor. Va más allá de lo puramente fisiológico: da cuenta de lo simbólico" (Le Breton, 1999, pp. 12,13).

En tercer lugar, la noción de sufrimiento ofrecida por Le Breton (1999), puede resultar compatible, desde mi punto de vista, con una aproximación constructivista. Es posible considerar al sufrimiento como una vivencia afectiva construida por el individuo en un contexto social, lo cual se opone a una visión del sufrimiento como algo que viene configurado desde una determinada realidad externa.

En este punto se hace necesario explicitar la postura epistemológica desde la cual se realiza este trabajo. La pregunta fundamental es si el sufrimiento (como cualquier otra experiencia humana), está determinado más en función de la situación que lo desencadena o más bien en función de la persona quien, en tanto inserta en un contexto cultural, le da un significado a esa situación y responde en coherencia con esa significación. La interrogante: ¿respondemos a una realidad objetiva o a nuestro propio mundo de significados? es epistemológica. La realidad que tanto placer o sufrimiento nos produce, ¿es algo que existe independientemente con sus características a la cual respondemos, o jugamos un papel importante en nuestra experiencia de realidad y por lo tanto de la visión que tenemos de ella? La respuesta a esta pregunta, la opción epistemológica que tomemos, nos sitúa en perspectivas diferentes frente al sufrimiento. Por ello, resulta importante plantear brevemente la postura epistemológica a partir de la cual se realizará el análisis de la relación entre modernidad y sufrimiento.

\section{2- Constructivismo}

\subsection{1- Conceptualización}

El constructivismo como corriente epistemológica sostiene "que nuestros conocimientos no se basan en correspondencias con algo externo, sino que son resultado de construcciones de un observador que se encuentra siempre imposibilitado de contactarse directamente con su entorno" (Arnold, M.,1997, pp. 2,3). Ya en la antigua Grecia esta postura fue planteada por el sofista Protágoras (año 444 a. C.). En un mundo en el que predominaba la noción de una verdad eterna e inmutable, Protágoras irrumpe con la idea de que "el hombre es la medida de todas las cosas: De las que existen, como inexistentes; de las que no existen como, no existentes" (Fragmento I, en: López, R.,1997). En este sentido, para López R. (1997) es posible afirmar que Protágoras fue el primer constructivista, sin embargo su planteamiento no sobrevivió y sus obras fueron desapareciendo en contraposición a otras orientaciones que se vieron fortalecidas y que dieron pie para el posterior desarrollo de la ciencia positiva.

Para López, R. (1997), desde una postura positivista, la ciencia tiene como propósito conocer y comprender el mundo en su carácter objetivo, libre de cualquier contaminación de carácter subjetivo. Sin embargo, desde comienzos del siglo $X X$ ha reaparecido la duda sobre la posibilidad de éxito de semejante empresa. Fue el matemático, físico y cibernético Heinz Von Foerster, uno de los primeros en plantear que en la tradición occidental es una ilusión pretender que "las propiedades del observador no entran en la descripción de sus observaciones" (en: López, R. 1997, p. 3). Por otra parte, Arnold, M. (1999), menciona que los estudios de Kuhn dan 
cuenta que ni la razón (racionalidad) ni las sensaciones (empirismo), han sido las bases que sustentan el desarrollo científico. Son las consideraciones previas, constituidas a partir de la fe que en ellas tienen las comunidades científicas. Consideraciones que entonces participan en las observaciones del observador. Por otra parte, señala que la Física cuántica sostiene que la sola presencia del observador con una mínima intervención, modifica el objeto observado. Así, en todo acto cognoscitivo, la relación observador - observado se vuelve más importante que el objeto, el conocimiento depende de la perspectiva del observador, lo que lo hace responsable de su configuración.

El cuestionamiento a la ciencia positiva permite redescubrir la antigua pero hoy renovada idea que afirma "que nos relacionamos con el entorno a través de experiencias activas que involucran, mutualmente, observadores con observaciones." (Arnold, M., 1999, pg. 2). Desde la perspectiva constructivista, lo que conocemos es resultado del observador y no de lo observado y es por medio del lenguaje que surge la idea o noción de objetividad. En este sentido, Arnold, M. (1999), destaca la invisibilidad que tiene para el observador su participación en lo que observa. Afirma que para Luhmann, aún cuando la información es el resultado de una selección que el individuo realiza dentro de un campo de posibilidades que el mismo prediseña, una vez realizada le aparece como propiedad del entorno. El individuo la experimenta como externa, como dato de la realidad. Esta idea es reforzada por la externalización que se realiza a través del lenguaje.

Así, para López, R.(1997), la realidad es el producto de nuestras percepciones y del lenguaje a partir de procesos de comunicación entre personas. La realidad es construida socialmente. (5) Aún en nuestra construcción personal de la realidad, tenemos con los demás miembros de nuestra comunidad bastante similitud en nuestras experiencias, dado que compartimos una misma biología y pertenencia a una determinada cultura, sin lo cual la mínima convivencia no sería posible. Maturana pone especial énfasis en el lenguaje en nuestra construcción de realidad: "el lenguaje resulta fundamental porque es el instrumento con que configuramos el mundo en dicha convivencia" ( Serrano, M. en Maturana, H., 2000, p. 35). Para Maturana, "toda nuestra realidad humana es social y somos individuos, personas sólo en cuanto somos seres sociales en el lenguaje (...) existimos como seres humanos sólo en un mundo social que, definido por nuestro ser en el lenguaje, es el medio en que nos realizamos como seres vivos y en el cual conservamos nuestra organización y adaptación" (Maturana, H., 1996, p. 80). Como señala Watzlawick (en López, R. 1997) la "realidad" es una convención interpersonal, aquello que un número suficientemente amplio de individuos han acordado definir como real.

Para Arnold, M. (1999), es esperable que a partir de estos hallazgos la epistemología ocupe un lugar central en la discusión en Ciencias Sociales. Ha habido una revalorización de la hermenéutica, de la fenomenología, de la etnometodología, así como un mayor interés por los métodos cualitativos. Del mismo modo, Opazo, R. (1992) sostiene que en oposición al realismo en el que tradicionalmente se ha situado la Ciencia, el movimiento que supone la relatividad del conocimiento ha venido adquiriendo una fuerza creciente, teniendo como base la idea que nos relacionamos con el entorno a través de experiencias activas que involucran tanto al observador como a lo observado, lo cual implica un claro cuestionamiento a la posibilidad de un conocimiento objetivo. Es así como la psicología cognitiva y, como señala Arnold, M. (1999), la nueva etnografía, la teoría de los sistemas sociales y la biología del conocimiento, aparecen como sólidas alternativas que ofrecen nuevas formas para el operar científico.

La Teoría Biológica del Conocimiento (Maturana, H. y Varela, F., 1984) afirma, desde el ámbito de la biología, que toda experiencia de conocer involucra inevitablemente al que conoce. De acuerdo con esta teoría, somos seres determinados estructuralmente, nuestro sistema nervioso 
es un sistema cerrado que opera con correlaciones internas, no aprehendemos una realidad externa, sólo experimentamos nuestra propia realidad. Maturana "sostiene que el mundo en que vivimos es el mundo que nosotros configuramos y no un mundo que encontramos" (Serrano, M. en: Maturana, H., 2000 p. 30). No podemos entonces hablar de un conocimiento objetivo de la realidad, como si hubiese algo afuera de nosotros que pudiésemos conocer independientemente de nuestra estructura.

Para Arnold, M. (1999), la conjunción de diferentes ámbitos disciplinarios tales como algunos que se han mencionado, han favorecido el surgimiento del constructivismo. Lo define como una "corriente epistemológica cuyos axiomas sostienen que nuestros conocimientos no se basan en correspondencias con algo externo, sino que son el resultado de operaciones de un observador, el que se encuentra siempre imposibilitado de contactarse directamente con su entorno." (p. 4). Sostiene que para el constructivismo el conocimiento emerge cuando se indican y describen observaciones, es decir, al hacer distinciones, cuyos resultados conforman un piso autorreferido para la emergencia de nuevas distinciones. Se conoce al observar y hacer descripciones de observaciones. Como plantea Bateson, G. (1977, en: Rodríguez, D.,sin fecha), la mente percibe "news of difference" que constituyen el puente entre lo que denomina "mapa" y "territorio", es decir, entre la percepción y la realidad.

Si para el constructivismo la búsqueda de una verdad objetiva es algo inalcanzable, el objeto de la investigación, como señala Arnold, M. (1999), se orienta a encontrar explicaciones que resulten buenas y útiles. Al respecto, resulta interesante el planteamiento que Maturana (1983) sostiene sobre el quehacer de la ciencia. Afirma que hacer ciencia es explicar. Entiende la explicación como una reformulación del fenómeno a explicar que un interlocutor acepta como respuesta explicativa. En el caso de la ciencia, ésta se configura a partir de una clase particular de explicaciones que deben satisfacer cuatro condiciones: un fenómeno por explicar, hipótesis explicativa, deducción de otros fenómenos a partir de la hipótesis indicando sus condiciones de observación y la realización de la observación ce otros fenómenos deducidos a partir de la hipótesis explicativa. No hay ninguna alusión al encuentro de una "verdad" sobre la realidad. Para Maturana (1983), son científicos todos aquellos que hacen explicaciones científicas y consideran la explicación científica como el criterio de validación de sus afirmaciones, "ni más allá ni más acá", como menciona.

La adscripción de manera más o menos radical al constructivismo se puede observar en diferentes disciplinas de las ciencias sociales. La Antropología y la Sociología, han incorporado, desde los inicios del siglo XX, esta perspectiva. A partir de la década de los sesenta, los modelos interaccionalismo estratégico, interaccionalismo simbólico, teoría de la acción estratégica, teorías de la practica y de la acción comunicativa, han sido utilizados para la explicación de la conducta humana en sociedad (Viveiros de Castro, E. 1998). Desde la década de los setenta, en la Antropología ha ido cobrando cada vez más vigencia el modelo interpretativo de Geertz, quien parte de la concepción del hombre viviendo en redes de significado creadas por él mismo (Geertz, C., 1973).

En el ámbito de la Psicología, se ha ido incorporando la idea que somos constructores de nuestras experiencias. Vale la pena destacar algunos enfoques en el área de la Psicología Clínica que han incluido la perspectiva constructivista, ya que históricamente ha sido el área de la Psicología más directamente ligada al problema del sufrimiento humano. En el ámbito de los enfoques sistémicos, por ejemplo, Coddou, F., (1992) sostiene que existen tres planteamientos epistemológicos respecto de la posibilidad de acceder a la realidad. Aquellos enfoques que plantean la existencia de una realidad objetiva, aquellos que plantean la imposibilidad de 
acceder a una realidad objetiva.- poniendo ésta entre paréntesis de forma coherente con la postura de Maturana y Varela - y las posturas constructivistas más radicales.

Los enfoques que incorporan el constructivismo, consideran que el terapeuta se encuentra fuera de toda posibilidad de acceder a una "verdad" que lo sitúe en un sitio privilegiado frente a su paciente, desde el cual tiene autoridad para saber qué está bien y qué está mal en la vida de éste. En el enfoque Interaccional Estratégico por ejemplo, interesa qué y cómo algo está, según el propio paciente, haciéndolo sufrir. Por otra parte, en relación a las explicaciones del terapeuta sobre la naturaleza de los problemas y su solución, se asume que éstas son un conjunto de opiniones que resultan útiles para lograr un propósito determinado y su validez radica no en si son o no "verdaderas" sino en su utilidad. Se parte de la premisa que la teoría es un "mapa" cuyo valor radica en ser una herramienta de ayuda que oriente el operar del terapeuta.

El enfoque cognitivo conductual por su parte, aún en su clara adscripción a la metodología empírica tradicional, también ha considerado en su desarrollo conceptual esta perspectiva. En las últimas décadas esta escuela ha venido incorporando las variables cognitivas, afectivas, e incluso las variables inconscientes en la explicación de la conducta. La irrupción del paradigma cognitivo significó un vuelco en la forma de concebir al hombre. La introducción de estas variables pone en duda la idea de un hombre pasivo, controlado por los eventos externos. La incorporación de las variables mencionadas supone un organismo cuyas características determinan qué constituirá o no un estímulo para él y la forma en que dicho estímulo operará. El concepto de estímulo efectivo (acuñado por Yates), hace referencia a la idea de un estímulo procesado por el individuo que adquiere su valor final en función del significado que se le otorga. La sola noción de estímulo efectivo cuestiona nuestra posibilidad para acceder a un conocimiento objetivo e independiente de la realidad (6).

Es importante destacar que más allá del grado de adscripción a una postura constructivista, el sólo hecho de considerarla pone en duda nuestro poder para sostener una "verdad" sobre la realidad y nos remite al poder y la fuerza que tiene la interpretación o significación que cada ser humano hace de sus acontecimientos. El hombre, a través de sus cogniciones y afectos participa activamente en la construcción de su experiencia de realidad,..."el hombre ya no es una 'tabla rasa', en la cual los estímulos del medio iban escribiendo su destino. El hombre es un ser activo, que procesa la información de acuerdo a sus estructuras y procesos, biológicos, cognitivos, afectivos e inconscientes." (Miranda, G y Thumala, D. 1995, p. 30). El sufrimiento entonces, también puede ser entendido como una experiencia construida.

\subsection{2- Constructivismo y Cultura}

Considerando lo expuesto relativo a nuestra calidad de constructores de realidad, podríamos hablar de distintos niveles de construcción o de construcciones "concéntricas". Al centro, en un nivel psicológico, nuestra vivencia íntima y personal de la vida, en el que es muy fácil encontrar diferencias entre las personas, dadas nuestras diferencias biológicas y nuestro devenir histórico personal. Así, habrían tantos universos psicológicos como personas. Luego, haciendo un salto arbitrario, podríamos hablar de un nivel cultural, en el que al ser miembros de una cultura compartimos con los otros, interactuamos, nos coordinamos, como señala Maturana, por medio del lenguaje. Compartimos una serie de códigos, en los que al estar todos inmersos - más allá de nuestras diferencias psicológicas individuales.- nos asimilamos. De este modo, entre dos miembros de una misma cultura habrá mayor similitud en la construcción de sus experiencias que entre personas de culturas distintas. 
Al hablar de cultura, se hace necesario hacer referencia a ésta también desde una perspectiva constructivista, con el propósito de ser consistente con el marco epistemológico de este ensayo. No es posible situar a la modernidad como aquello que es relevado de la cultura occidental como si fuera una propiedad de un objeto independiente de quien lo observa. Claramente la descripción dada de la modernidad es una visión configurada a partir de otras observaciones. Ahora bien, ¿Cómo definir la cultura, en este caso moderna, desde una aproximación constructivista?. La revisión bibliográfica es casi nula respecto de una definición de cultura desde esta perspectiva, no obstante fue posible encontrar por lo menos dos aproximaciones. Buxo, M.J. (1987 en: Serra, A., 1992) sostiene que "La cultura es una construcción constante de estructuras de realidad (...) es un instrumento simbólico para la comprensión y la predicción en el ámbito de as relaciones sociales que se modifica dinámicamente según las necesidades e intereses de grupos e individuos." ( p 36).

Si bien esta caracterización de la cultura hecha por Buxo alude a construcciones de realidad, no queda libre de caer en una reificación del concepto al no explicitar que la construcción de realidad es una distinción hecha por un observador. Por otra parte, aún cuando le asigna una función: "instrumento ... para la comprensión y predicción", no queda claro qué tipo de construcción es, en qué se diferencia de otras. Ello la hace más bien una definición funcional, pero no aclara qué la constituye.

Una segunda concepción de cultura, que puede ser considerada constructivista, es la que propone Penn (2001): "Culture consists of the systems of mental constructions people use to interpret and respond to themselves and the world around them." (pg. 267)

La conceptualización alude a una construcción de los individuos y es lo suficientemente sintética pera ser clara. Sin embargo, aún cuando Penn aclara posteriormente la diferencia con los sistemas de significado individuales, no está explicitado, en la misma definición, si se trata de sistemas de construcción mentales individuales o compartidos por un colectivo. Tampoco aclara qué se considera sistemas de construcción mentales, más bien, al igual que Buxo, hace referencia a su función: interpretar y responder.

Si bien estimo que las definiciones realizadas en función de las propiedades de un concepto son útiles, intentaré realizar una definición constructivista de cultura que de cuenta de aquellos contenidos que son construidos, ya que parte de éstos serán usados en el posterior análisis de este trabajo. Propongo la siguiente definición de cultura:

Una construcción de realidad a partir de operaciones de distinción de artefactos, ideas, creencias y supuestos que en su mayoría son compartidos, transmitidos (principalmente por medio del lenguaje) y aprendidos por un grupo determinado.

La construcción supone distinciones que son hechas generalmente por un observador experto, el que en su observación distingue tanto las similitudes de artefactos, ideas creencias y supuestos que hay entre los miembros de un grupo determinado, así como las múltiples diferencias que también son apreciables al interior del mismo grupo. En este sentido, al afirmar "que en su mayoría son compartidos y transmitidos", se reconoce la multiplicidad de características al interior de una cultura, pero, al mismo tiempo, para que un observador la distinga como una cultura determinada, diferenciándola de otra, debe observar una mayoría de similitudes, al menos de carácter general, que le den coherencia a su observación. Por otra parte, las distinciones pueden ser realizadas en distintos niveles. La cultura mapuche por ejemplo, resulta unívoca al compararla con la chilena, pero también es posible hacer distinciones al interior de ésta como la pehuenche, por mencionar alguna. 
Considerando la conceptualización de cultura planteada, tal como se distinguen subculturas, en un nivel más amplio, podríamos hablar de un nivel metacultural o paradigmático. En este sentido Dockendorff, C. (1990), propone una extrapolación del concepto de paradigma científico, acuñado por Kuhn, para la descripción de las características de una realidad metacultural a la que llama "paradigma cultural". Podemos entender el concepto de paradigma cultural como la distinción de un "conjunto de supuestos sobre la realidad y sobre el ser humano que subyacen a una visión del mundo que a su vez forma parte de los fundamentos de una determinada cultura" (p.3). De acuerdo con la autora, la noción de paradigma cultural resulta útil para hacer referencia a períodos históricos amplios y diferenciarlos entre sí sobre la base de los supuestos básicos que sostienen respecto a la visión del mundo. Es así como podemos hacer referencia a nuestro paradigma actual como moderno, científico o newtoniano-cartesiano para diferenciarlo del paradigma medieval que lo precedió. Un aspecto interesante del concepto de paradigma es que al ser un conjunto de supuestos sobre la realidad, éstos, como el mismo término lo denota, son suposiciones respecto de cómo es el mundo y la realidad pero no están sometidos a verificación, actúan en nuestra cultura y por lo tanto en nosotros sin que nos demos cuenta: son inconscientes.

De acuerdo con la extrapolación teórica de Dockendorff (1990), en un nivel cultural estos supuestos permanecen como tales hasta que se acumula una cantidad de problemas, anomalías o situaciones que no pueden ser resueltas o explicadas a partir del modelo imperante y que lleva a un período de crisis en el que, luego de la acumulación de nuevas perspectivas, se establece un nuevo conjunto de bases o supuestos: un nuevo paradigma. Mirado desde la perspectiva del cambio que plantean Watzlawick, P; Weakland, J; Fisch,R., (1986), lo que ocurre es un cambio de "tipo dos", se cambian las ideas implícitas en virtud de las cuales se solía operar. Este sistema de reglas o ideas ya no puede dar cuenta de las anomalías, por lo tanto lo que cambia es el sistema mismo y no lo que está en su interior. Por último, es posible suponer que la relación entre los distintos niveles descritos- psicológico, cultural y paradigmático - no es lineal, existe una interacción entre éstos dada por el lenguaje, que resulta en que el cambio en uno de los niveles puede afectar a los otros.

\section{3- El Sufrimiento como una experiencia construida}

El estudio del sufrimiento puede transitar por un eje que va desde el nivel individual psicológico hacia un nivel cultural o paradigmático. Puede ser abordado poniendo atención a las diferencias individuales en la construcción de experiencias, donde los factores biológicos y psicológicos cumplen un papel preponderante, o bien, como se ha resuelto para este trabajo, preguntándose por aquellos supuestos, creencias o ideas que pueden distinguirse como parte de una cultura o paradigma cultural y que influyen en la forma de significar el sufrimiento y por lo tanto, de construir esta experiencia.

Tal como señalé en párrafos anteriores, abordar el fenómeno del sufrimiento desde una mirada cultural requiere aproximarse considerando su dimensión simbólica. Como menciona Le Breton, D. (1999), analizar la relación del hombre con su dolor implica reconocer la trama social y cultural en que se encuentra, sin olvidar que también es el creador de los significados con los cuales vive. Para el autor, en la experiencia del dolor, "una información dolorosa (sensory pain) implica una percepción personal (suffering pain)." (p.112). Por ello, como se ha mencionado, se asume que es el significado condicionado culturalmente de la experiencia sentida como dolorosa, lo que constituye el sufrimiento. 
Para Le Breton, D.(1999), es claro que la sensación de dolor es en primera instancia una vivencia íntima y personal que parece escabullirse de todo intento de aislarlo o describirlo, así como de dar cuenta de su intensidad y naturaleza. En este sentido afirma: "El dolor es un fracaso del lenguaje ... el dolor asesina la palabra" (pp. 43, 44). El dolor crea una distancia con los otros al sumergir al que lo padece en un mundo inaccesible para los demás, "no hay duda que el hombre nunca está tan solo como cuando es presa del dolor." (p. 47). Ahora bien, esta experiencia, como señala el autor, muchas veces inefable, es más que un hecho fisiológico, es existencial, aún en el dolor físico no es sólo el cuerpo el que sufre, sino el individuo entero.

Una prueba de la participación del individuo como totalidad en la sensación de dolor se observa en las diferencias en el umbral de resistencia al dolor que existe entre diferentes culturas. Le Breton, D. (1999), señala que aún cuando el umbral de sensibilidad para el dolor es semejante para el conjunto de las sociedades humanas, el umbral de tolerancia en el cual reacciona el individuo y el comportamiento que le sigue, están básicamente vinculados con la trama social y cultural. La fisiología humana no funciona en una especie de virginidad o pureza biológica capaz de mantenerla fuera de la historia, de lo social, del inconsciente, sino que está atravesada por símbolos culturales y sociales.

"Igual que el hambre, el dolor tiene un arraigo biológico, pero de la misma manera que los hombres no sienten el hambre en el mismo momento, ni perciben los mismos sabores ni comen alimentos idénticos ni satisfacen tampoco los mismos deberes rituales atribuyendo a lo que comen el mismo significado, tampoco sufren de la misma manera ni de acuerdo con una misma intensidad de agresión; atribuyen a su dolor un sentido y un valor diferente según las orientaciones colectivas propias del medio en el que viven. Hacer del dolor un simple dato biológico es insuficiente en la medida en que su humanización es la condición necesaria para que se presente a la consciencia, y porque ente una realidad espacio temporal $y$ otra, los hombres no sufren del mismo modo ni en el mismo momento." (Le Breton, D. ,1999 p. 138)

El sentido que el individuo otorga es a partir de un determinado contexto, de una determinada cultura que le ofrece ciertas orientaciones de significación y no otras. En este espacio y a partir de su propias características individuales da un significado a su dolor y construye así su experiencia de sufrimiento. Por supuesto esta construcción no es, la mayoría de las veces, deliberada, simplemente "ocurre" de manera automática e instantánea. Algunos supuestos culturales, como se verá más adelante, influyen en la construcción de experiencias sin que los individuos estén conscientes de ello. El sufrimiento como fenómeno condicionado por la cultura es la sgnificación de un estímulo doloroso a partir de ideas, creencias y supuestos que son transmitidas, compartidas y aprendidas por los miembros de un grupo determinado, en otras palabras de su cultura.

Al hablar de construcción de experiencia en una determinada cultura, sostengo que es posible observar en la cultura moderna un sufrimiento que le es propio. Por supuesto no es la intención de este trabajo determinar cuáles son los problemas del mundo actual, "no hay consenso intelectual sobre los orígenes del malestar en la cultura contemporánea" (Brünner, 1999, p. 46). Lo que propongo son ciertas distinciones que espero sirvan para tener una visión de algunas particularidades del sufrimiento en la modernidad. En primer lugar, a partir de la descripción realizada de la modernidad, se pueden identificar fuentes de sufrimiento no observadas en épocas anteriores y, en segundo lugar, la significación que el hombre moderno hace de su propio dolor y construye por lo tanto su experiencia de sufrimiento, también tiene características modernas . 
En relación a los riesgos, por ejemplo, si bien el hombre siempre ha estado expuesto a ellos, en la modernidad el desarrollo tecnológico ha disminuido muchos de éstos pero han aparecido otros de gran magnitud. Como señala Brünner (1999), los miedos actuales no son los mismos de antes. En la Edad Media el hombre se encontraba en un estado de precariedad material en comparación al hombre moderno. Sus miedos eran a las calamidades naturales, hoy en cambio son los miedos y angustias relativas al hecho de tener que lidiar con la incertidumbre y los riesgos propios de la modernidad anteriormente descritos. Por otra parte, el autor sostiene que la incertidumbre se ve aumentada por la impresión de estar en un mundo de permanente cambio y a una gran velocidad. El aumento de incertidumbre genera la sensación de angustia propia del no tener algo estable de que sostenerse, los cambios son acelerados, "todo lo que parecía sólido se esfuma en el aire. El individuo no tiene a qué aferrarse." (p. 42). Lo descrito puede unirse a lo que Giddens (1999) se refiere con la idea de que en la modernidad la crisis es una situación normalizada. En un sistema expuesto permanentemente a cambios, muchas circunstancias pueden ser evaluadas como crisis, en un sentido amplio del término, lo que contribuye a generar un clima de inseguridad, preocupación y angustia para las personas.

El ánimo predominante de este tiempo, para Brünner (1999), es de miedo y ansiedad. La incertidumbre es de mayor alcance, hay miedo al holocausto nuclear, a las oscilaciones de la economía internacional con todos los efectos que ello tiene sobre el empleo y el bienestar de las personas. Ahora bien, tal como señala Beck (1998), la situación de amenaza no necesariamente implica una toma de conciencia de ésta, puede, por el contrario, provocar la negación por el miedo. La amenaza no cambia, pero su percepción puede fluctuar. Como bien destaca el autor: "Durante décadas se ha dicho que había que 'vivir con la bomba'. Pero luego millones de personas salen a la calle. La tranquilidad y la intranquilidad pueden tener la misma causa: la inimaginabilidad de un peligro con el que empero hay que vivir." (p.84). Así, aún la sensación de riesgo fuera de la conciencia es producto del mismo miedo a éste, tal vez es el resultado de un mecanismo de defensa, más o menos colectivo para poder vivir con él.

Parece coherente con las necesidades de sobrevivencia el uso de la negación para poder proyectar la propia vida aún en un mundo de riesgos. Sobre todo si éstos están fuera de las posibilidades inmediatas de ocurrencia. No sería normal despertarse todos los días con la sensación de angustia frente al uso de la bomba atómica si no se está en un estado de guerra. Se niega esa posibilidad hasta que no sea posible de seguir negándola (por ejemplo la inminencia de una guerra). Sin embargo, otras fuentes de riesgo e incertidumbre propias de ese tiempo sí parecen afectar de manera más cotidiana la vida de las personas. Las mismas fluctuaciones de los mercados internacionales tienen efectos más inmediatos en los individuos. Las crisis económicas de países lejanos al propio ya no son sólo de "otros". Sus efectos son globales. Las repercusiones en la economía local son fuentes de incertidumbre y por ello de miedo y angustia. El fantasma de la cesantía, los fracasos de proyectos económicos y laborales acechan más de cerca que la guerra nuclear. El propio proyecto personal, la elección de un estilo de vida, como habla Giddens, debe contemplar estos riesgos para configurarse.

Para Pucheau (1998), el predominio de una economía de mercado globalizada ha exigido que los procesos de modernización lleguen a diferentes sectores de la sociedad si éstos pretenden sobrevivir y mantener su presencia. Este proceso de modernización implica que la ideología política imperante esté en estrecha relación con un modelo de racionalidad económica que reduce el concepto de desarrollo a su dimensión puramente material. Es posible, a partir del análisis desarrollado por el autor, suponer que esta forma de desarrollo ha implicado subordinar algunas de las otras dimensiones del vivir cotidiano al crecimiento económico. Si esto es así, los niveles de competencia en el trabajo, por ejemplo, para mantener un lugar determinado, pueden 
llegar a grados que impliquen altos niveles de miedo, angustia y una de las enfermedades más comunes de estos tiempos: el stress (7). Hoy día ya se puede hablar de stress en los niños, debido a las exigencias de rendimiento que deben satisfacer para competir por vacantes en colegios. Colegios que serán lo suficientemente exigentes para que de ahí salgan jóvenes con capacidades para competir por un lugar en la universidad, y así, se puede observar una sucesión de exigencias que se deben ir cumpliendo para seguir compitiendo por un espacio en la sociedad que cada vez es menos seguro, que cada vez está más en riesgo.

En este contexto donde la lógica del mercado adquiere gran relevancia, el desarrollo de un proyecto y estilo de vida propios, si bien se da en un contexto de apertura a diferentes posibilidades, se realiza "en condiciones fuertemente influidas por los efectos normalizadores del capitalismo mercantilista (...) baste con afirmar que el capitalismo es uno de los principales aspectos de la modernidad y que el proceso de acumulación capitalista representa una de las principales fuerzas impulsoras que se hallan tras el conjunto de las instituciones modernas. El capitalismo mercantiliza en varios sentidos." (Giddens, 1995, p. 249). De este modo, para Giddens (1995), el proyecto de vida personal se transfiere, en mayor o menor grado, al de la posesión de los bienes deseados y al desarrollo de estilos de vida artificialmente constituidos.

Las necesidades individuales se concentran en la necesidad de poseer y consumir lo que ofrece el mercado. Se genera una valoración de los bienes mayor a su valor de uso, se les ve como aquello que puede aliviar las sensaciones de insatisfacción, lo que efectivamente ocurre de manera momentánea, no obstante produce nuevamente la frustración de nuevas y crecientes necesidades. "El mercado se alimenta de la infelicidad que genera: miedos, angustias y sufrimientos de la inadecuación personal inducida por él suscitan la conducta del consumidor, indispensable para su continuidad." (Bauman 1989, en: Giddens 1995, p. 251). Así, dentro de la propia lógica del mercado se construyen estados de insatisfacción y sufrimiento.

El desarrollo de la propia identidad en el marco de la modernidad se da en este contexto de nuevos riesgos e incertidumbres, mercantilizado y, como se describió anteriormente, carente de grandes discursos o relatos que den respuesta a la falta de certezas. El individuo es paradójicamente obligado a elegir en medio de la incertidumbre, un estilo de vida. Más allá de los recursos económicos, que por supuesto implican diferencias en las posibilidades de elección de los individuos, hay una serie de elecciones como por ejemplo, casarse o no, tener o no hijos, etc. que el individuo cada vez más se ve obligado a elegir a falta de una tradición que elija por él. El valor de la libertad, central en el proyecto moderno, muestra su lado difícil cuando enfrenta al individuo a la angustia de elegir su propio proyecto de vida. Ni la ciencia ni la razón, como se señaló anteriormente, ofrecen al hombre las certezas para hacer elecciones libres de angustia.

La relación descrita entre modernidad y duda radical, para Giddens (1995), no sólo resulta en un trastorno para filósofos, sino que es existencialmente turbadora para el hombre común. La libertad del hombre, estimulada por la modernidad, se acompaña de angustia. Ahora bien, es claro que para vivir la vida cotidiana se requiere de una actitud que ponga en paréntesis cualquier duda existencial y actuar "como si" éstas estuvieran resueltas. Tal como señala: "Para vivir nuestras vidas damos normalmente por supuestas cuestiones que, según han descubierto siglos de indagación filosófica, se derrumban bajo una mirada escéptica." (pg. 53). El mismo autor sostiene que ante el temor de verse abrumado por angustias que afectan las bases de nuestro sentido más o menos coherente de estar en el mundo, la conciencia práctica junto a las rutinas cotidianas que esta misma produce, ayudan a dejar en suspenso esa angustia dando respuestas y orientaciones para el vivir ctidiano, las que, vale la pena destacar, son más sostenidas afectivamente, por medio de actos de fe, que racionalmente. 
A diferencia de épocas premodernas, como se describió anteriormente, en la actualidad el individuo no cuenta con una autoridad determinante, "por más difusa que fuera, la tradición era, en un sentido importante, una autoridad única." (Giddens 1995, p. 246). La diversidad que ofrece la modernidad actual o postmodernidad se acompaña de la falta de una autoridad que diga "cómo es el mundo" y "cómo se debe vivir". En la premodernidad, la religión ocupaba ese lugar sin mayor resistencia. Para Giddens (1995), si bien las autoridades tradicionales no eliminaban la incertidumbre de la vida cotidiana en las culturas tradicionales, sí daba respuesta a la impredictibilidad misma de la vida diaria y a lo que se creía fuera del control humano. "La Iglesia reinaba sin disputas sobre la cultura (...) a sus hombres les cabía interpretar los prodigios y las señas, adivinar su sentido y revelarlo al pueblo" (Brünner 1999, p. 37). Actualmente al ser la autoridad tradicional una más entre otras, por ejemplo la ciencia, el individuo se ve obligado a organizar su vida siguiendo diferentes fuentes de autoridad, lo que si bien ofrece la ventaja de contar con varios sistemas expertos a quien consultar, también implica la evaluación personal de éstos mismos, a veces en conflicto (8), a la hora de tomar decisiones importantes, situación que generalmente se acompaña de miedo y angustia.

Del mismo modo que para Castells estamos en el fin del patriarcado, para Brünner (1995), la familia y la comunidad, estructuras que tradicionalmente han tenido un importante papel como punto de referencia y soporte para la vida personal, se han ido debilitando como tales, producto de los cambios que han sufrido en el último tiempo. Es cierto que se han desarrollado más otro tipo de relaciones, más elegidas, más contractuales, pero por ello, pienso, más susceptibles de ser terminadas o reemplazadas por otras. Este nuevo escenario, como ben señala el autor, "crea unas sociedades frágiles, angustiadas por la soledad, asustadas frente a la vejez y la muerte, inhóspitas y frías."( pg. 41). No se trata, como afirma Giddens (1994), de caer en la visión romántica de la comunidad cuando se comparan culturas tradicionales con modernas, pero es observable que a diferencia de otras culturas premodernas, en que las experiencias de dolor son compartidas a través de ritos (9), en la nuestra en general el sentimiento comunitario está ausente. La mayoría de las veces, para Le Breton (1999), el dolor nos encierra en nosotros mismos y refuerza un sentimiento de soledad difícil de romper. En la modernidad, cada uno es responsable de cargar con su propia tragedia, salvo en ocasiones vitales como el nacimiento, matrimonio y muerte, donde aún se mantiene la necesidad de compartir y ritualizar.

Aún cuando muchos destacan que el valor de los ritos radica en que ofrecen una manera estructurada para que los individuos canalicen la tensión y angustia de los tránsitos importantes de sus vidas, para Giddens (1995), con la falta de ritos se ha perdido algo más profundo. Afirma que los ritos de paso ponen en contacto a las personas con fuerzas más amplias que relacionan la vida del individuo con algo más allá de él. En el ritual se liga la existencia individual con marcos morales y con aspectos elementales relativos a la existencia humana. La pérdida del rito es por lo tanto también la pérdida del compromiso con tales marcos, independientemente de la ambigüedad que éstos hayan tenido o por muy relacionados que hubiesen estado a una práctica inspirada en la fe religiosa.

En síntesis, en medio de los riesgos y la incertidumbre propios de la modernidad, con altas posibilidades de sentirse en crisis por los continuos y vertiginosos cambios en el medio; con la angustia que acompaña a la libertad de elección; con la sensación de tener la responsabilidad individual por el propio proyecto de vida; proyecto que se configura en un mundo que sobrevalora el éxito, especialmente económico influido por un mercado que se nutre de la insatisfacción material que también a su vez alimenta; el individuo se ve enfrentado a la angustia sostenida de tener que competir permanentemente por lograr y mantener un espacio social. Por otra parte, el sostén que otorgaban las redes más estables y tradicionales, como la 
familia, ya no tienen la misma vigencia. Las personas también deben enfrentar, cada vez más por sí mismos, la incertidumbre que significa construir relaciones afectivas estables $y$ significativas.

Estas son algunas de las fuentes (10) de sufrimiento que se pueden distinguir en nuestros tiempos. Ahora bien, las respuestas que la modernidad ofrece a los individuos para enfrentar las experiencias de sufrimiento, también mantienen diferencias con aquellas practicadas en la premodernidad. Si observamos la forma en que las personas sufren, es decir construyen su experiencia de sufrimiento - al significar el dolor - y responden en consecuencia a ésta experiencia, veremos algunas particularidades propias de estos tiempos.

Ya se hizo referencia a la pérdida que ha venido ocurriendo de los ritos más tradicionales. Quisiera detenerme en esta característica por las implicancias más profundas que, pienso, tiene. A partir de lo señalado por Giddens, entiendo que en la pérdida del rito hay una pérdida de conexión con ámbitos de referencia existenciales que van más allá del propio individuo y que le proveen un marco de sentido (11) a su existencia y, por ello, un sentido o un valor a su dolor. En el rito hay una forma de sumergirse de manera acompañada y socialmente pautada en la experiencia, en este caso dolorosa. El hecho de poder darle un sentido al dolor favorece un sufrimiento más fácil al cual sobreponerse. Por otra parte, transitar por el sufrimiento, ayuda a su procesamiento emocional, lo que favorece su alivio (12).

La dimensión que ocupan los ritos en la vida cotidiana es cada vez menor. El mundo corre demasiado rápido y es poco práctico, para el ambiente competitivo de hoy, detenerse en un rito. El duelo por ejemplo, cada vez se expresa menos. Creo que el luto que antiguamente se guardaba no era sólo la formalidad de vestir de negro por muchos días, también era un espacio y un tiempo para sufrir. Probablemente los ritos, por diversas razones, van perdiendo su significado y sólo van reproduciéndose sus formas, las que obviamente quedan vacías de sentido. Cuando esto ocurre, es muy fácil que el rito, más bien esta "cáscara" de lo que era el rito vaya quedando en el olvido y hasta se encuentre absurda su práctica (no conozco a nadie que hoy encuentre razonable llevar luto estricto por cuarenta días).

La relación con el sufrimiento ha cambiado. Como bien señala Le Breton (1999), durante mucho tiempo el dolor era considerado parte de un destino, había una suerte de fatalidad que exigía sobreponerse por un período o por toda la vida. Sin embargo, a fines del siglo XVII, las investigaciones en química avanzaron en la elaboración de sustancias con efectos anestésicos. Lo interesante que muestra Le Breton (1999), es que los médicos no se entusiasmaron en un comienzo con estos métodos para aplicarlos para aliviar el dolor, éste les resultaba natural e inherente a su práctica. Pero la anestesia finalmente se incorporó a la práctica médica y cambió no sólo ésta misma, sino también supuestos culturales relativos al dolor, el que cada vez más se alejaba de la idea de algo inevitable, propio del destino.

La modernidad a transformado la relación del individuo con su propia salud y, como afirma Le Breton (1999), la ha vuelto un asunto puramente médico. El dolor ha perdido significado y el umbral de tolerancia disminuye a medida que se generaliza el uso de analgésicos así como también retrocede el valor que en el pasado se asociaba a la resistencia personal. "Los estudios revelan que el miedo a sufrir suscita un espanto claramente superior al propio hecho de morir. El dolor es en la actualidad un sin sentido absoluto, una tortura total (...) en una sociedad que ya no integra el sufrimiento ni la muerte como hipótesis de la condición humana." (p. 206) Según el autor, cada vez más personas apoyan el derecho a la eutanasia, cuya legitimidad gana cada vez más espacios. 
Para Le Breton (1999), los significados que ofrece la cultura y que son compartidos por muchos, hace posible la sensación de control y manejo de la situación que se sufre. Cuando esto pierde vigencia, el individuo se queda desprotegido, desnudo frente a su dolor. En la modernidad, la pérdida de sentido del dolor está ligado a su transferencia al plano médico. $\boxminus$ dolor se convierte en un asunto de especialistas, en una preocupación técnica, lo que deja al individuo común y corriente sin un propio asidero. El dolor es significado como algo opuesto a la salud de lo que hay que, obviamente, despojarse. Es fácil, a partir de esta significación del dolor, suponer que el sufrimiento sea cada vez más mal tolerado (como se mencionó anteriormente respecto a los umbrales de tolerancia). Los individuos han ido perdiendo los antiguos recursos para hacerse cargo por sí mismos de su sufrimiento. "El progreso de los analgésicos ha transformado la experiencia humana del dolor (...) las antiguas defensas culturales se volvieron anticuadas y fueron sustituidas por los procedimientos técnicos. En consecuencia el umbral de la tolerancia ha disminuido (...) considerado inútil, estéril, el dolor es una escoria que el progreso debe disolver, un anacronismo cruel que debe desaparecer." ( Le Breton, 1999, p.210)

Si bien la anestesia se restringe al alivio del dolor físico, se la considera un ejemplo de que el progreso "nos hará más felices", es decir "nos liberará" del dolor. La técnica influye en las concepciones de mundo y las va cambiando gradualmente: de la idea de una falta de control sobre el propio destino a la creencia del control btal. El cambio cultural descrito (13), como pérdida de la posibilidad de sentido del dolor, se puede observar en la búsqueda de otros tipos de anestesia. El sufrimiento psicológico muchas veces busca ser "anestesiado" por medio de actividades tales como el consumo de drogas, el alcohol, la permanente búsqueda de más y nuevas emociones - desde el aumento progresivo del llamado "carrete" en los jóvenes, las carreras peligrosas de autos, tirarse al vacío con una cuerda - el consumismo, etc. Cuando el estímulo ya no es suficiente ("desgraciadamente" los seres humanos nos adaptamos) se buscará obviamente uno más intenso. Lo que quisiera destacar aquí es el supuesto implícito de que hay que eliminar siempre el dolor y que algo externo al individuo (como una "anestesia"), es lo que le producirá la tan ansiada felicidad y falta de sufrimiento.

Pareciera que cada vez más el sufrimiento se ha "cosificado" como si fuera algo que un experto tuviese que "sacarle" al que lo padece. Hoy en día se "tiene" una depresión, algo anormal que hay que eliminar. En este sentido, Seligman (1992), hace referencia a la depresión "normal" como aquella que todos conocemos, que surge de las penas y pérdidas inevitables que nos toca vivir por el mero hecho de ser miembros de la especie homo sapiens. La reconocemos por sentirnos tristes y desesperanzados, nos volvemos pasivos y lentos, perdemos el interés por actividades normalmente placenteras, puede alterarse el apetito, disminuir el interés sexual, el deseo de hacer vida social, rendimos menos en el trabajo, dormimos mal; sin embargo, luego de un tiempo, misteriosamente la depresión empieza a ceder. "Normal depression is extremely common - it's the common cold of mental illness. I have repeatedly found that at any moment approximately 25 percent of us are going through an episode of normal depression, at least a mild form." (pg.55). El autor da cuenta de la diferencia que generalmente se hace en el ámbito médico que distingue la depresión normal de los trastornos depresivos: la depresión unipolar y la bipolar (14), consideradas enfermedades.

Esta llamada depresión normal por Seligman, resulta útil para ejemplificar la relación que el hombre moderno sostiene con su propio sufrimiento, ya que aún en su grado más leve, hace referencia al sufrimiento más común y más cotidiano de las personas y que es el que interesa en este trabajo. Tal como el autor menciona, se trata de el sufrimiento propio de la vida misma. ¿Por qué se le llama "depresión" si es "normal"? La palabra alude a algo enfermo, algo que no debe ocurrir. No sólo es mostrada esta concepción por Seligman, está también en nuestro 
vocabulario habitual. La facilidad con que actualmente las personas afirman estar pasando por una depresión es cada vez mayor (15).

Es cierto que se podría argumentar que actualmente se realizan diagnósticos más finos y que muchas depresiones que antes no eran diagnosticadas hoy, gracias a su detección, reciben tratamiento. Ahora bien, aquí nos enfrentamos a preguntas como las siguientes: ¿Hay más depresiones que antes porque el contexto es más deprimente?, ¿Será que son las mismas que antes pero hoy se diagnostican?, o ¿No será que lo que antes era enfrentado con más recursos personales hoy no ocurre así y entonces hay más depresiones?, o tal vez, ¿podrá ser que el observador moderno realiza una distinción entre lo que es un sufrimiento normal y uno anormal con criterios que jamás habría usado el hombre premoderno? Es factible pensar que la depresión, especialmente la "normal", es catalogada como tal a partir de los mismos criterios modernos donde el sufrimiento es cada vez más considerado una experiencia ajena a la normalidad. Volvemos a la epistemología. Cuando nos hacemos preguntas sobre la depresión ¿De qué depresión "realmente" hablamos? Podemos pensar que no es más que lo que una comunidad, en este caso de expertos, ha decidido definir como depresión, es decir como sufrimiento anormal. Visto así, la respuesta a las preguntas anteriores dependerá de los criterios que se estén usando para entender la depresión.

Desde la perspectiva individual, la Psicología Clínica - si bien ha venido incorporando de manera creciente una perspectiva constructivista - ha tenido históricamente un desarrollo fuertemente vinculado a una tradición no constructivista y a la Psiquiatría. En éste ámbito, la pregunta sobre el sufrimiento ha sido abordada a partir de un marco psicopatológico en el que se realizan diagnósticos validados no sólo clínicamente, sino que socialmente. Los especialistas deciden qué es un sufrimiento sano y qué no lo es, con el fin de poder diferenciar lo que se define como "normal" de lo descrito como "patológico". Para este propósito, existen criterios diagnósticos para los trastornos de salud mental y por lo tanto se han podido establecer indicadores que dan cuenta de estos trastornos en nuestra población. El manual diagnóstico DSM-IV (16), por ejemplo, establece cuándo el sufrimiento de un individuo debe ser diagnosticado como un episodio depresivo mayor, a la vez que determina criterios para realizar diagnósticos diferenciales con otros cuadros clínicos.

Resulta tentador entrar en la discusión relativa a la validez que puede o no tener una perspectiva que se sitúa desde fuera del sujeto a evaluar lo sano o no sano de sus experiencias. La postura clínica, se sustenta en un plano de autoridad en el que el especialista supone ser poseedor de un conocimiento de la realidad que le permite distinguir lo sano de lo enfermo. No considera que la salud es una definición producto de un consenso cultural entre miembros de un sistema. Así, cada vez que el especialista establece la distinción "sano" - "no sano" - ya sea para determinar un diagnóstico o para realizar investigación - está involucrado en su propia observación como miembro de una cultura, en un determinado lenguaje que establece códigos y distinciones.

La tentación de continuar esta discusión respecto de la validez de la perspectiva psicopatológica debe ser considerada con cautela. Lo relevante no es - para los propósitos de este trabajo - determinar que la perspectiva psicopatológica no resulta aportadora para el estudio del sufrimiento, ya que no se ha sustentado tradicionalmente en un marco cultural y/o constructivista. El sufrimiento desde la psicopatología ha sido abordado con propósitos clínicos. Su relevancia o pertinencia debe ser evaluada desde ese ángulo. Lo que importa es aliviar el sufrimiento y en este sentido ha mostrado ser útil. No importa, siendo consecuentes con una mirada constructivista, si es verdad o no lo que plantea, lo que interesa es que siva a su propósito. De hecho, las perspectivas constructivistas desarrolladas en Psicología Clínica no se 
sitúan, como se planteó anteriormente, desde un marco de autoridad para realizar un diagnóstico y sus criterios de validación no se remiten al conocimiento de una verdad, sino a la utilidad de sus procedimientos terapéuticos. Vale la pena destacar que desde que Eysenck (1952) planteara la duda respecto de la eficacia de la terapia, existen numerosas investigaciones que respaldan su efectividad en comparación al no tratamiento.(Opazo, 1992).

Lo que interesa destacar es que aún considerando su utilidad, la perspectiva psicopatológica no pone el acento en que los individuos son constructores de sus experiencias de sufrimiento en el contexto de una cultura. Esta contiene supuestos, ideas o creencias que influyen en los significados que las personas hacen de los eventos dolorosos a los que se ven enfrentados y que determinan, en gran medida, su construcción de la experiencia de sufrimiento, como se verá más adelante..

La perspectiva clínica no ha puesto énfasis en poder conocer cómo estos elementos culturales resultan incorporados en la significación del sufrimiento, ni cómo estos actos de significación configuran a la vez nuestra cultura en procesos dinámicos de subjetivación - objetivación. El poder que la cultura puede tener en la construcción del sufrimiento, patológico o no, no ha sido un ámbito de estudio mayormente considerado. El sufrimiento no es algo dado, fijo, predeterminado en el individuo. La cultura influye en nuestros modos de significación, por lo tanto en que algo sea significado o no como sufrimiento y en qué forma. Que ese sufrimiento pueda llegar a ser definido como patológico, depende de un observador que diagnostica a partir de la forma, duración e intensidad del sufrimiento que percibe, el que está mediado, no sólo por las características psicológicas del individuo, sino también por su cultura.

Ahora bien, es claro y coincido con la mayoría de los especialistas en que el sufrimiento es una experiencia determinada por múltiples factores. Sin duda, las diferencias individuales (biológicas y psicológicas), así como la gravedad de los estímulos que enfrenten las personas, tendrán un peso importante en su sufrimiento personal. Es la dimensión cultural la que interesa destacar en este trabajo. La forma en que la cultura participa en la construcción de esta experiencia, probablemente en una mayor proporción en la llamada depresión normal que en aquellas en que se supone una mayor determinación biológica, que son las menos, pero que aún en esos casos su definición como enfermedad es una decisión determinada culturalmente.

\section{Un sistema de observación del sufrimiento en la modernidad}

\section{1- Modelo de observación y explicación del comportamiento}

El sufrimiento humano, aún siendo una experiencia culturalmente determinada, ocurre individualmente en cada una de las personas al momento de experimentarlo. Por ello, es fácil centrar su estudio en el plano individual, lo que ha dado importantes luces sobre aspectos biológicos y psicológicos en su configuración, pero, al mismo tiempo y como se ha mencionado, no han sido consideradas muchas veces las variables culturales. Obviamente se "sabe" que estas variables participan, de hecho se han descrito fuentes de sufrimiento, como las mencionadas en el capítulo anterior, pero no se ha puesto mayor énfasis en conocer cuáles son aquellas creencias o supuestos culturales que participan en la experiencia individual de construcción del sufrimiento. Se sabe más respecto de las condiciones sociales que producen sufrimiento, pero menos de la forma en que la cultura media entre estas fuentes de sufrimiento y la construcción final que hace el sujeto de su experiencia. Es posible que esto se deba a que, al ser el sufrimiento una temática que en la modernidad se ha vinculado cada vez más al ámbito médico, su estudio se ha centrado mayormente en su dimensión individual con propósitos terapéuticos. 
Intentar comprender el sufrimiento desde la manera en que los individuos construyen su experiencia a partir de ideas, creencias o supuestos culturales se facilita con el uso de un sistema de observación. Ahora bien, la comprensión de la conducta humana ha sido el propósito principal de las Ciencias Sociales, donde cada disciplina, desde sus propias distinciones, ha aportado una mirada que, junto con las demás, permiten ir configurando una "mapa" para la comprensión del comportamiento humano. Claramente esta afirmación en principio parece demasiado simple e ingenua, ya que este "mapa" está lleno de piezas superpuestas que no encajan del todo entre sí y de espacios vacíos.

Sostengo que a pesar de los "vacíos y piezas desencajadas" observables en el mapa explicativo de las Ciencias Sociales, es posible encontrar visiones compatibles y útiles para la comprensión de los fenómenos. Por otra parte, no creo posible, desde una epistemología constructivista, usar como criterio de selección de piezas de este mapa, aquellas explicaciones "verdaderas"; considero más bien la alternativa de evaluar a utilidad que cada una de estas miradas o conjunto de explicaciones tenga para la comprensión de algún aspecto de los fenómenos en estudio.

Al respecto, la Psicología Social ha desarrollado diferentes conceptos que vinculan las experiencias individuales con el medio social en que se insertan los individuos. Leahey (1989), señala como Jerome Bruner ya en los años 50, junto a otros colegas realizaron diferentes estudios sobre percepción, en los que confirmaron la idea de que la personalidad y el trasfondo social del individuo que percibe desempeñan un papel en lo que el sujeto ve. Aun cuando sus experimentos generaron polémica, lo interesante es que en éstos se observa cómo el procesamiento cognitivo, que condiciona la respuesta del individuo, está influido por su medio social.

Si bien la Psicología Social cuenta con diversos conceptos para describir la construcción social o cultural de la realidad, como el de representaciones sociales por ejemplo, dichos conceptos no resultan del todo nítidos para la observación de la experiencia del sufrimiento que se intenta ofrecer en este trabajo. En este sentido, el modelo explicativo básico de la Psicología Clínica cognitivo-conductual para la explicación del comportamiento, puede ser ampliado para dar cuenta de la forma en que ideas, supuestos y creencias culturales condicionan la construcción de la experiencia del sufrimiento de los individuos, pero manteniendo siempre presente en la observación la consideración de las diferencias individuales. Sirve más a los propósitos de este trabajo incorporar a un sistema de observación clínico la dimensión cultural, que intentar mostrar la construcción que un individuo realiza de su experiencia de sufrimiento a partir de conceptos como el de representaciones sociales, el que no resulta del todo claro y que además no es evidente la forma de mantener presentes las diferencias individuales en la construcción de la experiencia. Como señala Giddens (1995) " La modernidad se ha de entender en un plano institucional; pero los cambios provocados por las instituciones modernas se entretejen directamente con la vida individual y, por lo tanto, con el yo." (p.9).

Considero al modelo cognitivo-conductual útil para la observación del sufrimiento pues sirve para mostrar cómo es a partir de las estructuras cognitivas, afectivas y biológicas personales, que se construyen las experiencias. Ahora bien, la psicología clínica se ha centrado en la identificación de aquellos esquemas personales que inducen a la producción y mantención de patologías, con el propósito de modificarlos terapéuticamente y producir alivio en las personas. Por ejemplo, una persona con un esquema cognitivo-afectivo pesimista, percibirá el mundo y construirá sus experiencias a partir de este pesimismo, lo cual fácilmente puede derivar en una 
depresión. Sostengo que así como hay diferencias individuales en las estructuras biológicas y psicológicas, también tenemos esquemas o estructuras de significado que compartimos con otros como grupo y que nos diferencian de otros por la forma que adquieren nuestras experiencias. Vuelvo de esta manera a la idea de construcciones "concéntricas" que aludí anteriormente. Al centro podemos observar nuestras construcciones individuales, en un nivel más amplio están aquellas construcciones de experiencias más comunes, propias de la localidad o país en el que estamos y, en un nivel más amplio aún, las construcciones de experiencia condicionadas por ideas, creencias o supuestos, propios de la modernidad, que compartimos con los demás en tanto individuos modernos.

En relación al modelo cognitivo-conductual, éste se diferencia del modelo conductual básicamente por la incorporación del individuo como sujeto mediador entre el estímulo y la respuesta. Tal como fue mencionado anteriormente, cambió la concepción conductista del hombre como una "tábula rasa", pasivo frente a los estímulos del medio. Actualmente el modelo sostiene una visión del individuo como partícipe en la construcción de sus experiencias a partir de sus propias estructuras biológicas, cognitivas, afectivas e inconscientes (17), lo cual hace al modelo compatible con una perspectiva constructivista.

Para los propósitos de este trabajo, creo que elementos del modelo que propone Opazo (1992), son lo suficientemente claros para ser aplicados a la observación del sufrimiento del individuo como una experiencia culturalmente determinada. A continuación se exponen brevemente aquellos aspectos extraídos del modelo que serán usados en este análisis:

Como todo modelo cognitivo, mantiene el esquema básico 'E-O-R", donde E son los estímulos ambientales (18), $\mathrm{O}$ es el organismo que procesa la información del medio y le da un significado y $R$ es la respuesta o conducta posterior.

Observando el modelo más de cerca, Opazo (1992), sostiene que los estímulos (E), son percibidos por la personalidad $(\mathrm{Pd})$ - $(\mathrm{O})$ en el esquema básico - desde la cual se les otorga un significado a partir de los sub-sistemas que la constituyen: biológico, cognitivo, afectivo e inconsciente, los que interactúan entre sí de manera sistémica. Así, para Opazo (1992), en el procesamiento de la información, el medio aporta el material que es transformado a través del procesamiento que realiza el individuo. En este proceso, cuando la significación biológica del estímulo es muy alta (por ejemplo un daño físico), el "material" tenderá a imponer en gran medida el significado, el que será más compartido entre diferentes individuos (dado nuestras similitudes estructurales biológicas) que aquel con menor significación biológica (el divorcio, por ejemplo). En este último caso, las estructuras psicológicas tendrán mayor participación en la configuración de la respuesta y, por ello, se observará una mayor diversidad en éstas dado las diferencias que presentan en los individuos estas estructuras.

Un segundo elemento que quisiera rescatar del modelo es que, como señala Opazo(1992), al sistema se puede ingresar por vías diferentes: estímulos del medio, pensamientos del propio individuo, afectos, etc. y donde cualquier cambio en alguno de los sub-sistemas afecta a los otros. Así, un cambio en los afectos puede cambiar los pensamientos o vice-versa, un estímulo externo podrá influir en el sub-sistema biológico y éste en el afectivo, etc. De este modo, cada influencia en algún sub-sistema, así como en el medio, genera procesos de retroalimentación al sistema total que le permiten regular sus propios procesos. 
El modelo de observación se resume de la siguiente manera:

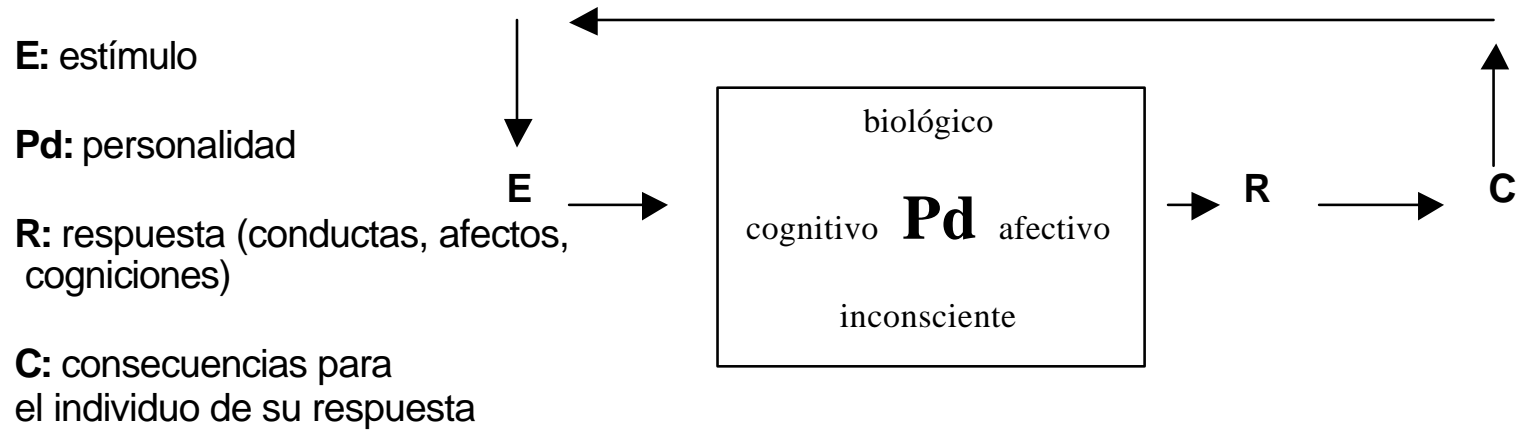

Me interesa destacar de este modelo la interacción que supone entre los diferentes subsistemas así como la relación de causalidad circular que se describe entre las respuestas del individuo y las consecuencias que éstas puedan tener en él. Consecuencias que al mismo tiempo llevan al individuo a confirmar o corregir su apreciación y respuestas y que son, muchas veces, proporcionadas por otros, es decir, por su medio social. Así, desde la propia cultura del individuo es evaluada su respuesta (y por ello reforzada o no validada). Un ejemplo de ello es la validación social que tiene la depresión que puede sufrir una persona por la pérdida de algún tipo de status social. Es culturalmente aceptado que ese tipo de pérdida sea algo lo suficientemente grave como para la aparición de una serie de síntomas depresivos. Esta validación de la interpretación de la situación y su respuesta (depresión), refuerza, y por ello mantiene, este tipo de interpretación con su consecuente conducta. Por el contrario, encontrar terrible y llorar por un hecho que culturalmente no es interpretado como algo grave es socialmente castigado, por ejemplo visto como ridículo, reduciéndose así su probabilidad de respuesta.

Ahora bien, es importante destacar que no es posible determinar "causas y efectos" de la conducta, lo que es definido como estímulo puede ser la respuesta a un estímulo anterior. A partir del modelo sólo se observa un momento, como si se sacara una fotografía de un devenir, siendo el observador quien puntúa la secuencia de los hechos como estímulos y respuestas.

En síntesis, a partir del modelo se observa una interacción individuo-ambiente donde un estímulo de la "realidad" (E) es significado por el individuo (Pd), a partir de sus esquemas personales, lo cual lo lleva a responder en coherencia con este significado (R) pudiendo generar consecuencias para sí mismo bajo la forma un nuevo estímulo (C). Por supuesto este es sólo un modelo de observación, un esquema que sirve solamente para ordenar ciertas distinciones de un observador con el propósito de comprender un fenómeno, el que no puede ser reducido jamás al modelo. A modo de ejemplo (muy simple y por ello no puede dar cuenta de la complejidad de una experiencia): un individuo recibe un telegrama $(E)$, lo que interpreta como la llegada de una mala noticia ( $\mathrm{Pd}$ : sujeto aprensivo) y se asusta $(\mathrm{R})$, lo que le induce a "pensar lo peor", hecho que se convierte en nuevo estímulo (E) aumentando la respuesta de miedo.

Basándome en este modelo, creo posible agregar aquellos supuestos, ideas y creencias culturales que dan sentido a la construcción de experiencia de sufrimiento que el individuo, desde su propia estructura biológica y psicológica, realiza del dolor que percibe. La cultura se refleja, por ejemplo, en las distinciones, categorías de pensamiento y lenguaje de los individuos, a partir de los cuales éstos ordenan sus percepciones y construyen interpretaciones. Ahora bien, tal como se mencionó, éstas se encuentran sujetas a una valoración social que las confirma o corrige. de acuerdo a sus propios parámetros. Del mismo modo, estas 
construcciones de experiencia retroalimentan este marco general de sentido que distingo como cultura.

Resulta importante dejar en claro que desde el punto de vista de la biología del conocimiento, no existen interacciones instructivas, por ello no afirmo que la cultura es una entidad externa que "entra" en la mente de los individuos y luego es proyectada al exterior como si fuera "algo" casi concreto. Es el individuo quien determina lo que constituye para él un estímulo a partir de su estructura. Ahora bien, ésta es el resultado de un devenir de acoplamientos estructurales con diferentes sistemas donde algunos de éstos son ideas, creencias y supuestos compartidos, transmitidos y aprendidos, muchas veces sin tener mayor conciencia de ello, pero que pueden ser inferidos, al realizar distinciones sobre la forma en que los individuos significan lo que para ellos es un estímulo y la manera en que responden a éstos (19).

\subsection{Aplicación del modelo planteado a la observación del sufrimiento en la modernidad}

\subsubsection{Incorporación de la dimensión cultural al modelo}

En la aplicación del modelo planteado para la observación del sufrimiento en los individuos, se intentarán describir algunos supuestos básicos que se encuentran a la base del período descrito como modernidad y que siguen por ello operando en la modernidad tardía. Como mencioné anteriormente, al conjunto de estos supuestos Dockendorff (1990) lo llama paradigma sociocultural. Recordemos que con este concepto alude al conjunto de creencias y supuestos sobre la realidad y sobre el ser humano que subyacen a una visión de mundo, la que al mismo tiempo es parte de los fundamentos de una cultura determinada. La noción de paradigma sociocultural resulta útil para hacer referencia a períodos amplios de la historia y para poder diferenciarlos entre sí a partir de aquellos supuestos básicos que condicionan una determinada visión de mundo.

Para Dockendorff (1988), una característica central de la noción de paradigma sociocultural es que la mayoría de las veces no somos conscientes que en nuestras observaciones nos basamos en distinciones que operan de manera implícita. Esas distinciones son las que Dockendorff (1990) define como supuestos básicos del paradigma sociocultural: "Es como el agua que el pez no puede ver porque jamás ha estado fuera de ella; no sabe que vive en ella. Nosotros como el pez, vivimos inmersos en 'la realidad' que damos por supuesta, sin tener clara conciencia de que no se trata estrictamente de la 'realidad' sino de un conjunto de ideas, supuestos, esquemas y modelos que tomamos por reales, no siendo más que un 'Paradigma'." (Dockendorff, 1988, pg.40).

Ahora bien, Dockendorff (1988) aclara que a diferencia del pez que no genera su propia agua, el ser humano construye sus paradigmas que después determinan su manera de entender y estar en el mundo. De alguna forma esto se relaciona con lo planteado por Geertz (1973), quien parte de la idea del hombre viviendo en redes de significado creadas por él mismo. Para Dockendorff (1988) la creación de paradigmas es inevitable para el hombre ya que "no puede vivir sino bajo un conjunto de ideas sobre la realidad" (pg.42). Destaca que la construcción de paradigmas no es una actividad deliberada de los individuos, a diferencia de las ideologías o filosofías. Los supuestos y creencias que lo constituyen surgen como el resultado del quehacer total del hombre que incluye todos los inventos, tanto de artefactos como de ideas. El paradigma va surgiendo a partir de las actividades de los individuos pero luego las ideas, supuestos y creencias que lo van configurando los trasciende y finalmente determina la creación de sus propias experiencias. 
De entre los contenidos que Dockendorff (1988) distingue de un paradigma, los supuestos parecen ser los que más lo definen y, por ello los supuestos serán los elementos destacados en este análisis. "Sin intentar una definición, podemos decir que un paradigma es un conjunto de supuestos sobre la realidad con que operamos habitualmente; y podríamos agregar: sin tomar conciencia de que lo tenemos." (pg.42).

Volviendo al modelo de observación del sufrimiento en la modernidad, éste se aplicaría de la siguiente forma: el individuo - determinado por su estructura, que es un sistema integrado compuesto por su biología, sus esquemas psicológicos cognitivos y afectivos, junto a un conjunto de ideas, creencias y supuestos culturales y paradigmáticos, en mayor o menor grado conscientes, y donde cada uno de estos elementos afecta y es afectado por los otros - percibe un estímulo doloroso (20) al que otorga significado y luego responde en coherencia con esta significación generando, la mayoría de las veces, consecuencias para el entorno y para sí mismo bajo la forma de un nuevo estímulo.

La incorporación de la cultura y del paradigma sociocultural al esquema planteado sería de la siguiente forma:

E: estímulo doloroso

In: individuo como un sistema

integrado

R: respuesta (conductas, afectos, cogniciones)

C: consecuencias para

el individuo de su respuesta

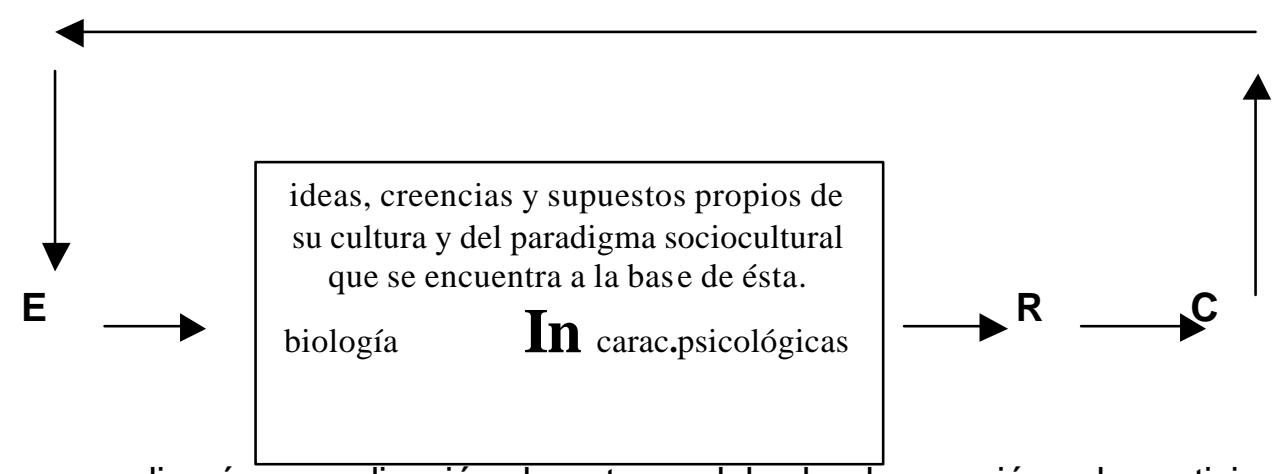

A continuación se realizará una aplicación de este modelo de observación a la participación de algunos supuestos del paradigma moderno en la construcción de la experiencia del sufrimiento, descrita en el capítulo anterior.

\subsubsection{Distinción de algunos supuestos del paradigma sociocultural de la modernidad que participan en la configuración de la experiencia del sufrimiento}

El contexto moderno presenta suficientes estímulos que pueden ser generadores de sufrimiento para el individuo. Por cierto, estímulos dolorosos han habido siempre en la historia de la 
humanidad, pero como se ha mencionado, lo que aquí interesa es la forma que éstos adquieren en la modernidad y la manera que el individuo tiene de responder al dolor que percibe. Ya se ha hecho referencia a lo largo de este trabajo a los estímulos dolorosos (21) modernos tales como la percepción de riesgos y de incertidumbre por mencionar algunos. Ahora bien, ¿de qué forma supuestos de el paradigma sociocultural moderno participan en la significación y respuesta que damos al dolor?

Sostengo que es posible observar supuestos de la modernidad que condicionan una respuesta evasiva al dolor, o bien un enfrentamiento dificultoso, en el que muchas veces resulta demasiado difícil sobrellevar y sobreponerse al propio sufrimiento. Por supuesto estas no son las únicas maneras de experimentar el sufrimiento, pero son formas probablemente generalizadas.

Partiendo por los supuestos que describe Dockendorff (1990), en primer lugar se encuentra aquel que supone que la realidad en la que vivimos es la única realidad. Como señala la autora, el hombre al hacerse cada vez más amo del mundo por medio del poder que le va dando la razón y la tecnología, va cambiando el contexto de sentido en que ubica su vida. Se transforma en sujeto al dejar de ser una criatura en manos de Dios. Con ello adquiere poder, se convierte en amo pero de este mundo, del mundo terrenal que puede conocer y controlar. "Lo trascendente, lo espiritual se le va haciendo cada vez más lejano y más ajeno. Al comienzo se produce un traslapo ente ambos mundos pero poco a poco uno va cediendo su hegemonía al otro. (...) El hombre se ve dividido entre dos lógicas diferentes y en el afán de compatibilizarlas limita su relación con lo trascendente a unas mínimas reglas morales y, a veces, a la participación en un ritual descontextualizado." (p. 48)

En un mundo que se va apartando de lo trascendente, Dockendorff(1990) destaca cómo la dimensión existencial va adquiriendo predominancia. Ya no interesa la salvación del alma, lo que vale es la satisfacción de las necesidades de aquello que es evidente de la existencia: la mente y el cuerpo. El objetivo de la vida se concentra en la satisfacción de sus necesidades. "Se postula que el hombre es gobernado por el placer y el dolor. Se cree que si se estimula la búsqueda de maximización del placer ello puede ser fuente de bienestar tanto para el individuo como para la sociedad. (...) Se acaba la vida ascética, las restricciones impuestas al despliegue de la creatividad del hombre para buscar su disfrute y bienestar material. El consumo es el fin del trabajo humano; el consumo es finalmente el objetivo de la vida humana." (p. 49)

Dockendorff (1990) señala que a diferencia del hombre medieval, para el que esta vida era un valle de lágrimas en la que el dolor lo preparaba para la felicidad que iba a encontrar luego en el paraíso, el hombre moderno, en cambio, bajo el supuesto de que la realidad existencial es la única realidad, el sentido de la vida va perdiendo su carácter trascendente y la búsqueda de la felicidad se convierte en la maximización del placer y la evitación del dolor. El dolor pierde todo sentido.

Si el dolor no tiene sentido y el desarrollo ofrece múltiples oportunidades de apartarse de él, parece absurdo sufrir. Como señala Le Breton (1999), "Sólo puede asumirse el dolor considerándolo una experiencia personal que tiene un sentido". (p. 108). En la era de la anestesia, en la que se supone que la búsqueda del placer y la evitación del dolor es la base de la felicidad, no es fácil dar un sentido al dolor, por ello la alternativa de evadirlo es la más lógica (22).Además, como se señaló antes, el aumento de la anestesia se contrapone a la disminución de los umbrales de tolerancia al dolor. Por otra parte, recordemos que la capacidad del hombre 
para adaptarse lo empuja a buscar constantemente nuevos y más intensos estímulos que le den placer (por ejemplo la droga o la sexualidad de consumo que describe Castells).

Como se planteó en el capítulo anterior, la evitación del dolor no es lo mismo que procesarlo y por medio de ello lograr su alivio. La evitación, generalmente no consciente, es no darle un espacio, es negarlo en defensa propia a través de las múltiples ofertas anestésicas que nos ofrece el medio: consumismo, drogas, alcohol, búsqueda de sensaciones intensas que lo aplaquen o llenen el vacío que da la falta de sentido. La evitación del dolor no sólo es buscado por la persona, es demandado por el medio, no corresponde mostrarlo. El dolor es parte de la intimidad del individuo, no es compartido y menos ritualizado en comunidad. No se debe sufrir frente a otros ni perturbarlos con el propio sufrimiento, al que ellos tampoco pueden darle sentido.

La evitación del dolor no lo elimina, lo encierra. Este encierro no se sostiene fácilmente, el dolor puede abrirse camino con más fuerza o tomar otros rostros para ser absorbido: los síntomas psicosomáticos son una clara muestra del dolor no procesado. Simonton (1997), describe cómo en su trabajo con pacientes con cáncer, es observable el temor de hablar de aquello que constituye un miedo significativo para estos pacientes: el temor a la muerte o a una recaída de la enfermedad. Señala: "Los sentimientos que se suprimen constantemente, se hacen mayores y más poderosos, del modo que el miedo a la recaída y a la muerte puede llegar a ser abrumador. Además los pacientes se sienten a veces muy distanciados de sus familias por no poder discutir abiertamente sus preocupaciones." (p. 137).

Por otra parte, suele ocurrir que la evitación del dolor, en otras palabras el "no escucharlo", no permite "oír" las razones de su existencia - como problemas que deben ser resueltos 0 enfermedades que requieren tratamiento - lo cual puede aumentarlo, impidiendo que el individuo lo siga evitando, transformándose así en mayor sufrimiento.

En el modelo de observación planteado, la evitación del dolor es la respuesta a la falta de sentido que se atribuye al dolor provocado por algún estímulo. Por supuesto, cada persona lo evitará en mayor o menor grado dependiendo de la interacción de sus sistemas biológico y psicológico con los supuestos culturales descritos.

A continuación, se aplicará el modelo de observación, sólo con el propósito de mostrar lo planteado, en dos ejemplos. Sin duda cualquier experiencia humana es más compleja que una descripción a partir de un modelo, pero el uso de éstos facilita la exposición de algunas ideas puntuales. Es importante aclarar, además, que los ejemplos que se darán corresponden a lo que podría llamarse una cultura media occidental moderna. Como se afirmó anteriormente, la cultura no puede ser considerada un todo homogéneo, de este modo es posible que muchas de estas ideas no sean aplicables a algunos grupos minoritarios en el contexto moderno, tales como algunos grupos religiosos o étnicos.

Un ejemplo que con frecuencia se observa en las consultas psicológicas, es la de personas con ritmos de vida muy exigentes, que viven prometiéndose a sí mismas y a sus familias que cambiarán a un ritmo más saludable cuando logren lo que se han autoimpuesto cumplir. Consultan por síntomas físicos (cefaleas, dolores a la espalda, etc. ), y reconocen estar bebiendo o fumando en mayor cantidad. Saben que están estresados, pero su petición es cómo no sentirse así pero sin bajar su ritmo de vida, ya que ello "no es posible" por una lista infinita de razones. Generalmente los síntomas los padecen hace bastante tiempo y vienen en aumento. Una actitud frente a éstos ha sido automedicarse una serie de analgésicos que sirven en el momento inmediato, pero luego los síntomas vuelven a aparecer de manera más intensa. 
En el esquema el ejemplo se graficaría de la siguiente forma:

E: estímulo doloroso: cefaleas, dolores de espalda.

In: supuestos: supuesto de que el dolor no tiene sentido (en esta vida, la única que tenemos, la felicidad es la maximización del placer, la satisfacción de las necesidades del cuerpo y de la mente, para ello es válido buscar más y mayores fuentes de gratificación como el éxito (económico y social) que hay que mantener y en lo posible aumentar)

biología: vulnerabilidad mayor para manifestar síntomas de stress físicos como cefalea y dolor de espalda (y no otros, por ejemplo úlcera)

psicología: altos niveles de autoexigencia, por ejemplo.

R: respuesta: automedicación de analgésicos, aumento del hábito de fumar y del consumo de alcohol

C: $\quad$ consecuencias: aumento de los síntomas dolorosos : cefaleas y dolores de espalda

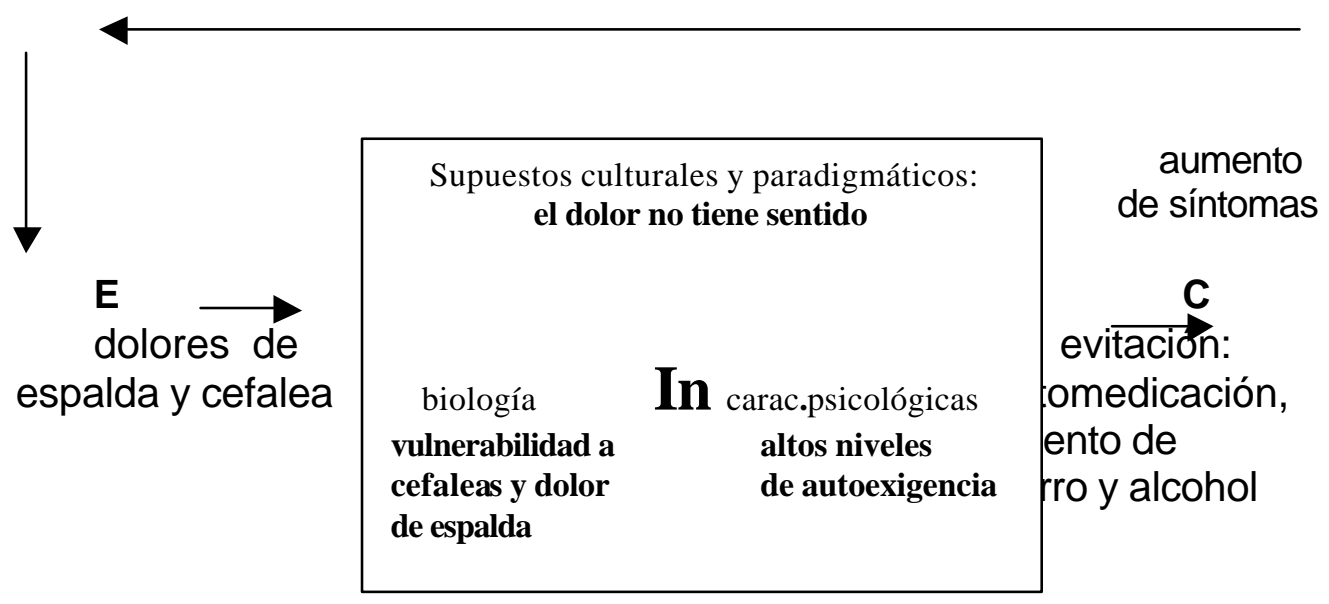

¿Qué ocurre cuando no se puede evitar el dolor? A partir de los supuestos descritos, es posible suponer que ante la inevitabilidad del dolor, el individuo que ha crecido en un medio que por una parte fomenta su anestesia y, por otra, no le da ningún sentido, probablemente se encuentre con insuficientes recursos para enfrentarlo. No sabrá cómo darle un sentido y lo significará como algo absurdo que no "debe" ocurrirle, que no es "justo" padecer, que no es "normal" y debe ser eliminado, generalmente por un especialista. Aquí aparece lo que Seligman denomina la depresión "normal". Por supuesto, un individuo con mayor vulnerabilidad biológica a la depresión y con esquemas psicológicos favorecedores de ésta ( por ejemplo: "debo hacer todo bien siempre o no valgo nada"), podrá desarrollar un cuadro depresivo. Pero, la mayoría de las veces el sufrimiento toma la forma de una depresión "normal" que, finalmente y de todos modos, es llamada depresión. 
Un ejemplo observado también en la consulta (psicológica), que se podría afirmar que representa a varios de su mismo tipo: Una mujer joven, de unos 24 años, de situación socioeconómica acomodada. Plantea tener una "depresión" (reporta los síntomas de una depresión normal). No tolera estar padeciéndola, demandándole al terapeuta su pronta eliminación. Casi se podría suponer que la deprime verse deprimida. La razón, el término reciente de un pololeo. Estima que su situación es "grave" ya que por la edad que tiene es posible que se quede soltera. Nada parece confortarla ni convencerla de que a su edad la falta de pareja no significa eterna soltería. No quiere vivir lo que le está tocando enfrentar pero no sabe qué hacer con su sufrimiento, sólo cree que debe deshacerse de él. No se plantea la posibilidad de vivir el duelo de una pérdida, le asusta el dolor y cuando no puede negarlo lo sobredimensiona y sólo puede pensar en fantasías catastróficas. Si no se produce el alivio después de un tiempo, o no logra aceptar con más tranquilidad su momento de sufrimiento por una pérdida, que no significa necesariamente más que eso, probablemente derive en una depresión mayor si su estructura psicológica colabora en ello ( por ejemplo dificultad para llenar su vida si no está en pareja) o su biología (vulnerabilidad a la depresión).

Para el ejemplo expuesto, el modelo se aplicaría de la siguiente forma:

E: estímulo doloroso: término del pololeo

In: supuestos: supuesto de que el dolor no tiene sentido (en esta vida, la única que tenemos, la felicidad es la maximización del placer, la satisfacción de las necesidades del cuerpo y de la mente. Para ello es válido buscar más y mayores fuentes de gratificación, como la pareja por ejemplo, que además evita los sentimientos de soledad). depresivo)

biología: vulnerabilidad mayor para la depresión (en caso de presentar un cuadro psicología: dificultad para estar sola

R: respuesta: baja tolerancia a su propio sufrimiento, alta demanda por su eliminación

C: consecuencias: eventual aumento de los síntomas (desarrollo de un cuadro depresivo)

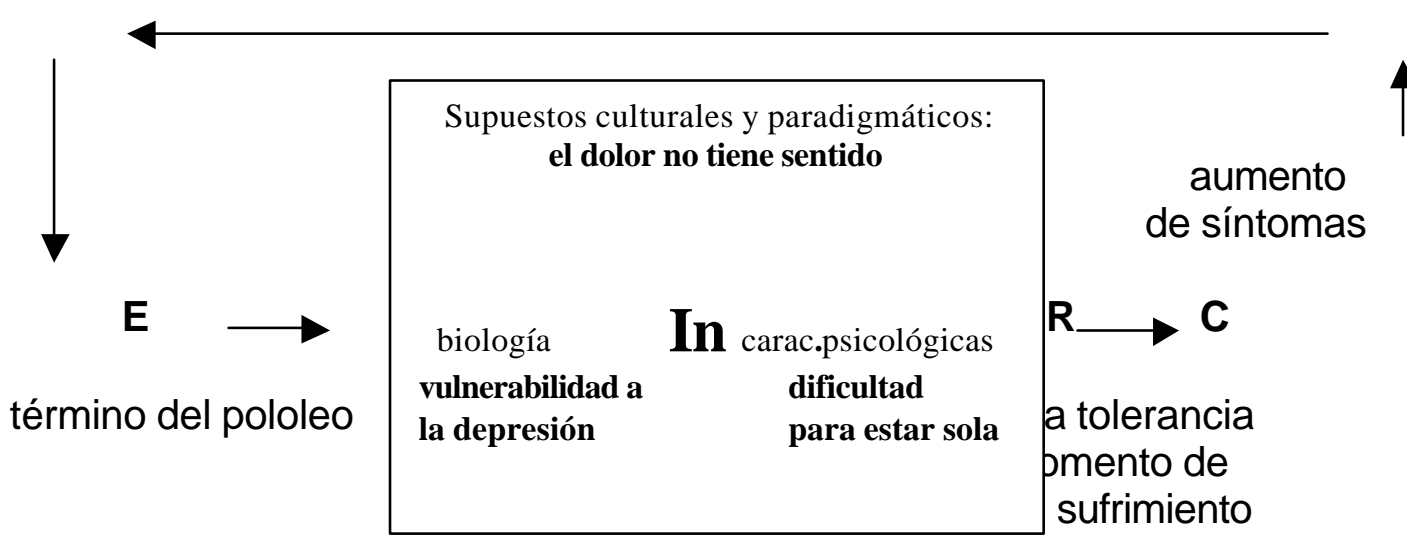


Los dos ejemplos expuestos son situaciones de sufrimiento comunes en nuestra sociedad actual. No son situaciones extremas, son cotidianas. Responden a expectativas modernas que son validadas socialmente: el éxito como fuente de satisfacción de necesidades materiales y sociales (por lo tanto no se puede dejar de competir y rendir aún cuando el cuerpo diga lo contrario) y la exacerbación del amor romántico como solución a la propia soledad o vacío (lo que llena la vida se reduce al pololeo). Su no satisfacción, entonces, es temida o mal tolerada.

Si tomamos la descripción de la modernidad en relación a sus fuentes de sufrimiento, veremos cómo éstas se constituyen en gran medida como estímulos dolorosos a partir de supuestos culturales tales como los mencionados: la creencia de que esta realidad es la única realidad, lo que fomenta el supuesto que la felicidad es el resultado de la máximización del placer y la evitación del dolor, el que bajo estas creencias no tiene sentido. Las fuentes descritas no pueden sino ser dolorosas y por ello generadoras de sufrimiento bajo esos supuestos, al mismo tiempo que son producto de esta misma racionalidad moderna: La creación y percepción de riesgos y de incertidumbre, la mercantilización de los estilos de vida en los que se reduce el concepto de éxito al ámbito material, $\$$ sustentan en la idea de progreso material. Bajo los supuestos descritos no hay demasiadas alternativas a continuar en la misma lógica que genera estas fuentes de sufrimiento que luego son padecidas.

La pérdida de la tradición, en la que el sentimiento de trascendencia y destino era más común, se une al predominio de los supuestos descritos. En la modernidad importa esta vida, la única que tenemos y por ello es el placer lo que le puede dar un sentido a la propia existencia, la que es responsabilidad del propio individuo y no de un destino o voluntad que lo trasciende y que es interpretado por una autoridad religiosa. La libertad se acompaña de tener que elegir sin mayores certezas y muchas veces reconociendo autoridades que pueden estar en conflicto entre sí. El rito que conectaba al que sufría con lo trascendente y que le permitía darle un sentido y procesarlo está hoy, bajo los supuestos descritos, cada vez más fuera de lugar.

Por otra parte, la familia patriarcal que otorga al individuo un sentido de pertenencia poco cuestionable, no ofrece la misma estabilidad de antes. Más allá de lo insatisfactorias que resultaban muchas veces las relaciones familiares tradicionales, especialmente para las mujeres, la familia patriarcal era un espacio de relación æsegurado para el individuo (muchas veces ése era el problema que podía generar sufrimiento). Al ser la familia tradicional paulatinamente reemplazada por nuevas relaciones, que así como se construyen se pueden desarmar, el individuo queda cada vez más solo con sus decisiones, con su libertad y también con sus angustias. En ese marco es libre de buscar aquello que más lo satisfaga (que le reporte más placer en esta vida, que es la única vida). No es extraño suponer que en esas condiciones la insatisfacción en la relación de pareja, por ejemplo, sea poco tolerada: es absurdo sufrir si puedo encontrar placer y bienestar en otra relación. Lo que muchas veces ocurre, y no es raro de observar, es que la nueva relación tampoco brinda la satisfacción esperada, hecho que genera gran frustración y sufrimiento. Por supuesto no estoy suponiendo que la imposibilidad de ruptura sea una solución a los conflictos de pareja. Ello sería, por lo menos, una postura ingenua y rígida. Simplemente dejo lanzada la interrogante: ¿Es la nueva pareja la que no satisface, o es la dificultad para enfrentar las frustraciones y el dolor inevitable presentes en cualquier relación (obviamente en unas más que en otras) lo que impulsa a la ruptura, con el sufrimiento que ello implica?

Ahora bien, la posibilidad de construir la experiencia de sufrimiento bajo otros supuestos se ha observado en individuos que justamente se han destacado en nuestra cultura por haber podido acoger y dar un sentido a su propio dolor. En la historia de la humanidad, y aún en la 
actualidad, se encuentran muchos ejemplos de personas que han experimentado el sufrimiento de una manera que los ha fortalecido, como aquellos que dieron su vida por una causa o por sus principios, así como personas que le han dado un sentido de desarrollo personal 0 espiritual, tales como Victor Frankl (1982) o Etty Hillesum (1985), por mencionar algunos. Personas que en situaciones límites (campos de concentración), pudieron acoger su sufrimiento de una manera que no sólo les permitió sobreponerse a él, sino también engrandecerse.

Ahora bien, como señala Aranguren (sin fecha), acoger el dolor no es lo mismo que resignarse. Acoger es poder ir más allá del presente, es no centrarse en el momento y perderse en él, es integrarlo en un proyecto que va más allá del hecho presente y que por lo tanto trasciende al individuo.

"Seguían torturando al flaco. Oía sus gritos mezclados con los insultos de los torturadores. Necesitaba urgentemente encontrar algo del ser humano que yo supuestamente era y me estaba abandonando a la carrera. (...) ¡No hablar!, No hablar era la consigna. (...) Hablar es peor que la muerte (...) ...resistí, pero a fuerza de una tremenda mística y de los miles que en ese momento me acompañaban" ( Rojas, C., 1988, pp. 17,18)

El relato corresponde a una mujer del MIR que fue torturada en tiempos de la dictadura. La tortura es heroicamente resistida en función de un sentido mayor que subordina el dolor individual a una causa colectiva. El dolor configura un sufrimiento que representa valor, coraje, consecuencia.

El sentido de trascendencia, como se aprecia en el testimonio anterior, no necesariamente es religioso y su particularidad radica en que puede cambiar la experiencia de sufrimiento al darle un sentido. Como bien señala Le Breton (1999): "La primera defensa contra el dolor reside en el significado que aquel le da. Cuando nada permite inscribirlo en un entramado significante, el sufrimiento se vive al desnudo, desgarra sin matices, y con frecuencia acarrea el desaliento o la depresión." (p. 88).

Para Frankl (1984), el hombre sufre hoy por "un abismal complejo de falta de sentido, acompañado de un sentimiento de vacío, razón por la que me inclino a hablar de un vacío existencial" (p. 9). Ante la pregunta por la génesis de este vacío, explica que el hombre, a diferencia del resto de los animales, carece de instintos que le digan qué tiene que hacer y "a diferencia de los hombres del pasado, el hombre actual ya no tiene tradiciones que le digan lo que debe ser." (p. 11). La forma en que ese vacío existencial se manifiesta en la actualidad, no necesariamente es en la "angustia existencial", sino más bien en la búsqueda constante de satisfacciones. "La angustia existencial dejó de estar de moda, y se difundió el 'pasarlo bien' y el 'vivir el momento'. (Gissi, 1992, p. 361).

El sentido de trascendencia, entendido como Aranguren, puede cuestionar el supuesto que la felicidad es la maximización del placer (que debe ser creciente y continuo) y la evitación del dolor. La felicidad se ligaría al sentimiento de ser parte de un sentido mayor que va más allá del propio sujeto. Claramente ello también es un supuesto, el que puede o no ser religioso. En el ejemplo que sigue (el fragmento de una carta que escribe Teilhard de Chardin a su prima), la felicidad y el sufrimiento son experiencias concebidas de manera diferente a la moderna. La felicidad está en el sentido de pertenencia a algo que trasciende al individuo, más que en la gratificación personal, y el sufrimiento surge del apego al propio valor: 
“¿Por qué tener tanto apego a ti misma, hasta el punto de desconcertarte si no te hallas tan desarrollada, favorecida y utilizada como quisieras? ¿Qué es nuestro éxito individual comparado con el placer divino? Además, ¿qué ambiciones son las nuestras? Ser vistos, hacer algún ruido a nuestro alrededor, crear en nuestra pequeña esfera de acción una agitación perceptible... ¿Es eso realmente lo que sine para medir el valor de una vida? ¿O es que no sabemos nosotros que el valor real de nuestra existencia se medirá finalmente por el grado de fidelidad y obediencia que hayamos desplegado en la subordinación a la voluntad divina, cualquiera que haya sido la tarea brillante o humilde en que hayamos servido? Fundamentalmente, sé feliz, te lo digo. Vive en paz. Sé infatigablemente dulce." (Teilhard de Chardin, P. 1965, p. 83)

En el ejemplo anterior, Teilhard de Chardin invita a su prima a mirar de una forma diferente su frustración e insatisfacción personal. Cuestiona el valor de la individualidad y concibe la felicidad como la entrega a algo trascendente, en este caso religioso. No es importante el éxito personal, lo que importa es la armonía con lo divino. El sufrimiento surge del apego, en este caso al valor personal, el que al frustrarse provoca sufrimiento. Tal como menciona De Mello (1998), "Estar libre de todo apego a la vida significa estar feliz de vivir y estar feliz de abandonar la vida... El mundo está lleno de sufrimiento; la raíz del sufrimiento es el deseo-apego; la supresión del sufrimiento es el abandono del apego" (p.33). Claramente una afirmación como ésta cuestiona supuestos fundamentales de nuestra cultura, ¿Es posible vivir sin apegos? Según De Mello lo es. De hecho, un propósito fundamental y común a diferentes religiones, es el logro de un desapego de lo mundano y de una mayor conexión con una dimensión espiritual de la vida. Ahora bien, más allá de las creencias religiosas, lo que interesa mostrar en este punto es la posibilidad de concebir el sufrimiento de una manera que no es la que se sustenta en supuestos básicos de nuestra cultura.

Los testimonios presentados son claramente extremos. Ahora bien, en la vida cotidiana, cuando el dolor es integrado como parte de ella puede ser experimentado de una manera que permite no sólo corregir aspectos de la propia vida que lo requieren, sino también desarrollar una visión más amplia de la existencia. Enfrentar el dolor genera una experiencia de sufrimiento que obliga a mirar más allá de donde siempre se mira. El sufrimiento puede cuestionar las bases más profundas de nuestra existencia, exige el replanteamiento de aspectos vitales, en el dolor hay una oportunidad de desarrollo y fortalecimiento. Como señala Raúl Zurita:

"La felicidad podemos entenderla, en cierto sentido parece que nos fuese debida. Pero el dolor es a menudo incomprensible. Sin embargo, el sufrimiento es exactamente lo que nos da la magnitud de la existencia, nuestro consentimiento a ella, nuestra afirmación permanente. Si uno se queda en silencio puede escuchar el sonido de su propia respiración; si se queda más en silencio podrá oír los latidos de su corazón. Pero si oye bien ese latido verá que él repite un sí. Es un sí-sí-sí. En cada segundo de la vida optamos por vivir. Esto es dramático y real porque hay seres en el mundo que dicen no y se expulsan de la vida. Eligen no vivir. El estado de sufrimiento es escuchar ese sí (...) el hombre feliz no escucha ese sí porque la vida le está encima, absoluta. El que sufre debe luchar por su vida, elegirla en cada instante de sus sufrimiento (...) El amor surge de la confrontación de ese sí con la posibilidad de la nada, del no.(...) Por eso aquello que algunos han dado en denominar Dios se siente más cerca de los lugares donde han ocurrido desastres (...) El dolor es el altoparlante para hacernos más humanos, más tolerantes, más conscientes del milagro y del amor de la existencia." (El Mercurio, 12/03/00) 
Identificar la forma en que supuestos culturales, que como tales no vemos, participan en la construcción de nuestras experiencias, es un proceso que no se puede dejar de lado en la comprensión de fenómenos tan complejos como el sufrimiento, en el que claramente lo cultural y lo metacultural o paradigmático se entretejen con la individualidad al momento de configurarse la experiencia humana. La descripción realizada - que contrasta ejemplos más típicos de sufrimiento en la modernidad con experiencias que dan cuenta de otros supuestos - apoya la idea que estas ideas implícitas condicionan las experiencias. El reconocimiento de la forma en que supuestos de nuestra cultura moderna occidental operan en nosotros nos abre un poder de elección mayor al que tenemos. Podemos elegir seguir con ellos o cuestionarlos, podemos cambiar nuestras experiencias, entre ellas la forma en que enfrentamos el sufrimiento. ¿O acaso no somos libres? (para no dejar de ser modernos).

"It is possible to suffer with dignity and without. I mean: most of us in the West don't understand the art of suffering and experience a thousand fears instead. We cease to be alive, being full of fear, bitterness, hatred and despair. God knows, it's only too easy to understand why. But when we are deprived of our lives, are we really deprived of very much? We have to accept death as part of life, even the most horrible death. And don't we live an entire life each one of our days and does it really matter if we live a few days more or less?" ( An Interrupted Life: The Diares of Etty Hillesum 1941-43)

\section{Conclusiones}

A partir de la visión del sufrimiento humano como una experiencia construida y condicionada por la cultura, es posible observar particularidades que son propias del sufrimiento moderno.

El hombre ha sufrido siempre y probablemente siempre lo hará. Ahora bien, es interesante distinguir la forma que este sufrimiento toma en diferentes contextos culturales. La llegada de la modernidad en occidente situó al individuo paulatinamente bajo un conjunto de ideas, creencias y supuestos culturales que cambiaron su relación con el mundo. La razón y la ciencia cuestionaron las creencias y modos de vida más tradicionales y con ello cambió la forma de vivir de las personas.

Junto al desarrollo de la modernidad, el individuo se ve sumergido en un mundo de riesgos e incertidumbre, en un continuo y vertiginoso cambio, sometido a la angustia de tener que elegir el rumbo de su vida y ser por ello responsable de sus éxitos así como de sus fracasos y propia tragedia personal. Éxitos y fracasos que la mayoría de las veces son medidos con la vara del logro económico y material, lo cual le impide salirse de la constante competencia para tener un espacio en la sociedad. Además, el ámbito de relaciones garantizado que bien o mal ofrecían las redes más estables y tradicionales, como la familia, se ve progresivamente debilitado y a cambio surge la necesidad de tener que construir permanentemente las relaciones afectivas de apoyo requeridas.

El debilitamiento de los tejidos sociales, en especial de la familia, dificulta el enfrentamiento del sufrimiento. Se sufre cada vez más en una soledad que a veces es abismal, y no se cuenta con respuestas para asumir el sufrimiento. Bajo las condiciones descritas, no es difícil la aparición de la angustia, stress o depresión. Muchos de estos síntomas, que reflejan la cara oscura de la modernidad, son fácilmente anestesiados por ella misma. Ahora bien, la anestesia permite evadir, negar el sufrimiento, pero la mayoría de las veces no lo elimina. Su forma de aparición puede tomar otros rostros, como conflictos, crisis, enfermedades físicas, por mencionar algunos. 
El desarrollo de la modernidad bajo supuestos que reducen la vida a su plano puramente existencial, es un elemento que, probablemente entre muchos, ha ido dejando de lado la búsqueda de trascendencia o de sentido. De este modo, la búsqueda del placer y la evitación del dolor se configuran cada vez más como las motivaciones centrales del hombre. El sufrimiento en la modernidad va perdiendo sentido y el hombre se vuelve cada vez menos tolerante a él, por ello le resulta tremendamente difícil enfrentarlo cuando es inevitable. El mayor recurso del hombre moderno frente al sufrimiento es la evitación y para eso la modernidad le ofrece múltiples formas de anestesia, pero ante su inevitabilidad se queda, muchas veces, sin herramientas para enfrentarlo. No sabe darle un sentido, lo que hace aún más difícil su padecimiento pudiendo, en algunos casos, aumentarlo: deprimirse por enfrentar el sufrimiento de una pérdida.

La posibilidad de construir la experiencia bajo supuestos que se contraponen a los descritos puede observarse en el testimonio de personas que han podido darle un sentido, muchas veces trascendente, al sufrimiento y con ello no sólo han podido sobreponerse, sino que también se han engrandecido a través de él.

El reconocimiento de la forma en que supuestos culturales operan en la construcción de las experiencias, en este caso del sufrimiento, ayuda a poner en evidencia la participación que tienen en este proceso de construcción. No somos conscientes de estos condicionantes y vivimos creyendo que la forma en que experimentamos la vida es la única posible. Estamos atrapados en nuestra propia estructura de creencias y supuestos. Comenzar a evidenciarlos puede aumentar la comprensión de nosotros mismos, así como la libertad para experimentar nuestra vida de otras formas posibles, en este caso nuestra experiencia de sufrimiento.

\section{Bibliografía}

ARANGUREN, J. (S.F.). "Diversos Sentidos de la Palabra Dolor". Instituto de Antropología y Ética. Universidad de Navarra. España.

ARNOLD, M. (1997). "Introducción a las Epistemologías Sistémico/Contructivistas". Cinta de Moebio, № 2. Departamento de Antropología. Universidad de Chile.

contemporánea".

(1999). "Problemas Epistemológicos. Constructivismo sistémico y la Sociología

BAEZA, M. (2001). Apuntes de clases: Metodologías Cualitativas. Magíster en Antropología y Desarrollo, Universidad De Chile.

BECK. U. (Compilador) (1999). "Hijos de la Libertad". Fondo de Cultura Económica Argentina, S:A:

BRÜNNER, J.J, (1999). "Globalización Cultural y Posmodernidad". Fondo de Cultura Económica Chile S.A.

CASTELLS, M. (1999). "La Era de la Información”. Volúmen II El Poder de la Identidad. Ed.Siglo XXI. Mexico/ España.

CODDOU, F.( 1992). "Alcances Epistemológicos y Conceptuales en relación al Enfoque Sistémico". _Integración en Psicoterapia. Opezo, R. Editor. Ed. CECIDEP. Santiago. 
DELGADO, J. M., GUTIÉRREZ, J. (coord.). (1999). "Métodos y Técnicas Cualitativas de Investigación en Ciencias Sociales”. ED. Síntesis. Madrid.

DE MELLO, A (1998). "Medicina del Alma”. Ed Lumen. Argentina.

DOCKENDORFF, C. (1990). "El Surgimiento de un Nuevo Paradigma: estudio exploratorio de élites científicas y espirituales chilenas". Tesis para optar al grado de Licenciado en Sociología. Pontificia Universidad Católica de Chile, Instituto de Sociología.

Osorio, J.,Weinstein, L. Editores.

(1988). "Notas sobre la noción de Paradigma". La Fuerza del Arco Iris.

El Mercurio (12/03/2000) Suplemento Artes y Letras

EYSENCK, H. J. (1952). "The Effects of Psychotherapy : an evaluation". Journal of Consulting Psychology, 16, pp.3199 - 324.

FISCH, R.; WEAKLAND, J; SEGAL, L. (1984). "La Táctica del Cambio. Cómo abreviar la Terapia". Ed. Herder, Barcelona.

FRANKL, V. (1982). “El Hombre en Busca de Sentido”. Ed. Herder, Barcelona.

GARCÍA CANCLINI, N. (1990). "Culturas Híbridas”. Ed. Grijalbo, Mexico.

GEERTZ, C. (1992). “La Interpretación de las Culturas”. Ed. Gedisa, Barcelona.

GIDDENS, A. (1995). "Modernidad e Identidad del Yo”. Ed. Península, s.a.Barcelona.

. (1994). “Consecuencias de la Modernidad”. Ed. Alianza, Madrid.

GOFFMAN, E. (1992). "Internados”. Ed. Amorrortu, Buenos Aires.

HILLESUM, E. (1985). "An Interrupted Life: The Diares of Etty Hillesum 1941 - 43". Ed. Washington Square Press, N.Y.

KRAUSE, M. (1995). "La Investigación Cualitativa: Un campo de posibilidades y desafíos". Revista Temas de Educación, №7.

LE BRETON, D. (1999). “Antropología del Dolor”. Ed. Seix Barral, Barcelona.

LEAHEY, T. (1989). "Historia de la Psicología”. Ed. Debate, Madrid.

LÓPEZ PÉREZ, R. (1997). "Constructivismo Radical de Protágoras a Watzlawick". Excerpta №7, Universidad de Chile.

MATURANA, H. (1983). "Fenomenología del Conocer". Revista de Tecnología Educativa. Vol. 8 Nos. $3 / 4$. . (1996). "Desde la Biología a la Psicología”. Ed.Universitaria, Santiago. 
(2000). "El Sentido de lo Humano". Ed. Dolmen, Santiago.

\& VARELA, F.(1984). "El Arbol del Conocimiento". Ed. Universitaria, Santiago.

MIRANDA, G.; THUMALA, D. (1995). "Psicoterapia y Orientación: Algunas reflexiones". Perspectivas, № 1. Carrera de Trabajo Social, Universidad Católica Blas Cañas.

MUCCHIELLI, A. (Dir.). (1996). "Diccionario de Métodos Cualitativos en Ciencias Humanas y Sociales". Ed. Síntesis, Madrid.

OPAZO, R.(1992). "Fuerzas de cambio en Psicoterapia:un modelo integrativo". Integración en Psicoterapia. Opezo, R. Editor. Ed. CECIDEP. Santiago.

3. . (1983). "Avances en Terapia Cognitivo Conductual". Terapia Psicológica, año 2, № №2. . (1984). "Cognición y Afecto en Terapia Conductual". Análisis del Comportamiento,

PENN, W. (2001). "Quick Ethnography”. Altamira Press, England.

PROGRAMA DE LAS NACIONES UNIDAS PARA EL DESARROLLO (PNUD).(1998) "Desarrollo Humano en Chile". Ed. Trineo, Santiago, Chile.

PUCHEU, A.(1998). "Ideas sobre los efectos psicológicos de los procesos de modernización". Revista Chilena de Psicología. №2 Vol.19 pgs. 49 - 56.

RODRÍGUEZ, D. (S.F.). "Teoría de Sistemas: una visión global”. (Artículo)

ROJAS, C. (1988). "Recuerdos de una Mirista". Carmen Rojas, Santiago, Chile.

SELIGMAN, E. P. (1992). Learned Optimism: How to change your mind and your life. Pocket books, New York, USA.

SERRA, A. (1992). "Design Culture. Estudio etnográfico de los proyectos de investigación de la School of Computer Science de Carnegie Mellon University, un "computer - intensive campus" (norteamericano)". Tesis Doctoral. Departamento de Antropología Cultural e Historia de América y África. Universidad de Barcelona

TEILHARD DE CHARDIN, P. (1965). "Génesis de un Pensamiento". Taurus Ediciones. España.

VIVEIROS DE CASTRO, E. (1998). "Society". Encyclopedia of Social and Cultural Anthropology. Barnard, A.; Spencer, I. Editores. Routledge, G.B.

WATZLAWICK, P.; WEAKLAND, J.; FISCH, R. (1986). “Cambio”. Ed. Herder, Barcelona. 


\section{Notas}

(1) Si bien resulta tentador extenderse y realizar una discusión sobre estas causas dadas por el autor, ello apartaría la lectura del foco de interés mencionado para este capítulo.

(2) Es interesante la estadística relativa a este tema: En Estados Unidos, la convivencia antes del matrimonio es más la regla que la excepción. Un poco más de la mitad de estas convivencias terminan antes del año, el $40 \%$ se transforma en matrimonios, de éstas el $50 \%$ se divorcia, el $75 \%$ vuelve a casarse con una posibilidad de divorcio mayor a la media total de matrimonios. (Castells, 1999).

(3) Es importante mencionar el análisis que realiza Castells (1999) respecto de la configuración de grupos o comunidades como reacción a las tendencias individualizadoras imperantes, tales como el fundamentalismo religioso, el nacionalismo y las comunas territoriales. Es interesante observar cómo el fortalecimiento de dichos grupos al verlos como reacciones defensivas, puede servir para confirmar la idea de una creciente tendencia individualizadora.

Por otra parte, Giddens (1994), menciona la existencia de posturas antagónicas a la idea de un "declive de la comunidad", como la llama. Para quienes propugnan esta idea, la vida comunal o sobrevive bajo las circunstancias modernas o bien renace con fuerza. No obstante, Giddens hace referencia a una falta de precisión en las discusiones respecto de lo que se entiende por "lo comunal" y, si bien hay lazos que se mantienen como por ejemplo el parentezco, el papel que tiene hoy ha cambiado.

(4) Un ejemplo del peso social en la construcción del sufrimiento está claramente descrito en el trabajo publicado por Erving Goffman en su libro "Internados". En éste se aprecia cómo más allá de la patología mental que puede sufrir un paciente psiquiatrico, parte importante de su identidad de paciente y por lo tanto aspectos importantes de su sufrimiento psicológico están dados por la interacción social en la que participa como enfermo. La experiencia dolorosa de ser un paciente psiquiátrico, más allá del posible beneficio y efectividad de los tratamientos, se consituye tanto por la patología como por la definición social de enfermo. Su condición y por lo tanto su experiencia es una construcción social. "A menudo se encuentra registrado un denunciante, alguien que entabla contra el agresor la acción que ulteriormente lleva a hospitalizarlo... De este comienzo social arranca la carrera del paciente, dondequiera localice el comienzo psicológico de su enfermedad mental." (Goffman, E., 1992, pg. 139).

(5) Para López, R. (1997), el constructivismo se aparta de una postura "estrecha y psicologista" como describe al solipsismo, ya que el hombre como constructor de realidad es entendido en un sentido colectivo. El énfasis está puesto en la cultura y no en la mera existencia de determinados objetos porque una subjetividad incuestionable los crea.

(6) Es importante mencionar que al interior de este enfoque actualmente hay una discusión respecto de si es posible o no acceder a un conocimiento "verdadero" de la realidad, de hecho existen posturas más bien intermedias, " en términos epistemológicos, me inclino a favor del realismo crítico y de un constructivismo moderado ...desde esta perspectiva, no habría un conocimiento puro de la realidad, ni habría ni certezas ni objetividades plenas. Pero si existiría una realidad independiente de nosotros, hacia la cual podemos orientar nuestro conocimiento en algún grado."(Opazo,1992, pg. 419).

(7) Stress:, entendido como la presencia sostenida de un estado de alarma, con todas las concomitantes fisiológicas que ello implica y que al ser mantenidas en el tiempo pueden generar daños al organismo. 
(8) Un ejemplo puntual pero significativo: Una mujer jóven, profesional, casada, madre de dos niñas, le han diagnosticado un cáncer y una de las indicaciones es que se someta a un tratamiento de quimioterapia. A los pocos días de enterarse de esta noticia se da cuenta que está embarazada. Sus médicos le sugieren abortar con propósitos terapéuticos ya que no puede someterse hasta después de los tres primeros meses de embarazo a la quimioterapia, porque pondría en riesgo al feto, y esperar ese tiempo la pone en riesgo a ella. Se trata de una mujer religiosa que decide discutir su situación, no sólo con los médicos sino también con sacerdotes, los que probablemente tendrán una opinión diferente, para finalmente tomar sı propia decisión. Aparte del grado de sufrimiento que conlleva una situación de esta envergadura, en el ejemplo se destaca la asignación de diferentes fuentes de autoridad para finalmente quedar sola con toda la responsabilidad de su decisión.

(9) Le Breton (1999), compara la experiencia de dolor físico en una comunidad sioux en que es compartida y ritualizada, con la vivida por pacientes en salas de quimioterapia, en la que no hay mayor contacto entre éstos y donde se evita "invadir" o "molestar" al otro con el propio dolor.

(10) Es claramente una puntuación de la secuencia de hechos (como afirma Watzlazick), hacer referencia a "fuentes" como si fueran "causas" asumiendo una linealidad que claramente no es posible para un fenómeno tan complejo como el sufrimiento. Por ello, quiero dejar en claro que mi intención al hablar de "fuentes" es simplemente una distinción con propósitos relativos a la exposición.

(11) En contraposición a lo que es absurdo, sin una razón de ser.

(12) En los velorios por ejemplo, el deudo se ve de alguna manera invitado recurrentemente a contar cómo fue la muerte de su ser querido. Una y otra vez lo cuenta y llora. Su llanto es validado socialmente. Es aceptado que esté mal, que cuente y llore por lo que le ha ocurrido. Este "pasar una y otra vez por la experiencia "facilita el proceso psicológico de duelo requerido para el posterior alivio.

(13) Entendido bajo la definición propuesta como cambios que se distinguen en la construcción de realidad a partir de operaciones de distinción de artefactos, ideas, creencias y supuestos que son compartidos, transmitidos y aprendidos por un grupo determinado.

(14) La diferencia que señala Seligman entre estas dos es la presencia o no de manía. La manía es una condición psicológica contraria a la depresión: euforia, sentimientos de grandeza, verborrea, intensa actividad, por mencionar algunos síntomas. La depresión bipolar siempre involucra manía, en cambio la unipolar nunca se acompaña de manía y se diferencia de la depresión normal por la severidad de los síntomas. Para Seligman, es más evidente el componente físico en la depresión bipolar, la que responde generalmente al carbonato de litio, que en la unipolar. Sostiene - a diferencia del criterio médico más común que la identifica como una enfermedad - que la depresión unipolar y la normal son lo mismo salvo por la intensidad de los síntomas. Las diferencias de opinión implicarán diferencias en el tratamiento, el cual podrá centrarse más o menos en la medicación dependiendo de la postura asumida. También la imagen del paciente sobre lo que le ocurre y su actitud frente a ello diferirá en una u otra postura.

(15) Al respecto la revista Times destaca la masificación que ha tenido el uso de antidepresivos como el "Prozac". Hace referencia a una posible nueva era de "psicología cosmética" en la que el cambio de características de personalidad (mediante el uso de medicamentos) podría llegar a 
ser tan simple como cambiar la coloración del pelo. Aludiendo a una antigua publicidad norteamericana de tintes "Ya que sólo tiene una vida, ¿por qué no vivirla como una rubia?" agrega ¿por qué no como una rubia con buen ánimo? (Octubre, 1993)

(16) Manual Diagnóstico y Estadístico de los Trastornos Mentales. El número IV señala que es su cuarta versión revisada.

(17) A diferencia de otros modelos psicológicos, como el psicoanálisis principalmente, el modelo cognitivo-conductual, por su apego a la metodología científica, tardó en incorporar al inconsciente como otra dimensión determinante de la conducta humana.

(18) Para efectos de este trabajo, se entenderá por estímulo aquello que el individuo, como sistema determinado estructuralmente, reconoce como perturbación que viene del entorno.

(19) El reconocimiento de la participación de la cultura en la creación de la experiencia individual puede ser observado en la siguiente afirmación de Pallavicini (2000), "En psiquiatría es muy importante la creación local de conocimiento porque, a diferencia de otras especialidades, está culturalmente muy arraigada. Un cuadro psicótico en los mapuches chilenos, por ejemplo, no sólo tiene particularidades debido a la etnicidad, sino también debidas al contexto cultural". (El Mercurio, 12705/00).

(20) Por estímulo doloroso se entiende aquel que es así definido socialmente. Por ejemplo, de todas las pérdidas posibles, sólo las definidas culturalmente como dolorosas serán percibidas de esa forma. Por supuesto, mientras más peso biológico tenga el estímulo, más compartida será su percepción como doloroso, pero luego, como señala Le Breton (1999), su significación podrá presentar más variabilidad entre diferentes culturas.

(21) Podemos hacer referencia dichos motivos como estímulos dolorosos, usando la palabra "doloroso" en un sentido amplio, incluyendo aquellos percibidos como "estresantes"

(22) Respecto a la evasión del propio dolor, podría discutirse si es o no sufrimiento ya que no es evidente el hecho de que haya sido percibido conscientemente por el individuo y significado. En todo caso, para los propósitos de este trabajo, dicha interrogante no será considerada por lo extensa que puede ser su discusión. Lo que importa es el hecho que la experiencia de dolor o sufrimiento es negada. 